AN ANALYSIS OF POTENTIAL STREAM FISH

AND FISH HABITAT MONITORING PROCEDURES

FOR THE INLAND NORTHWEST

Annual Report 1999

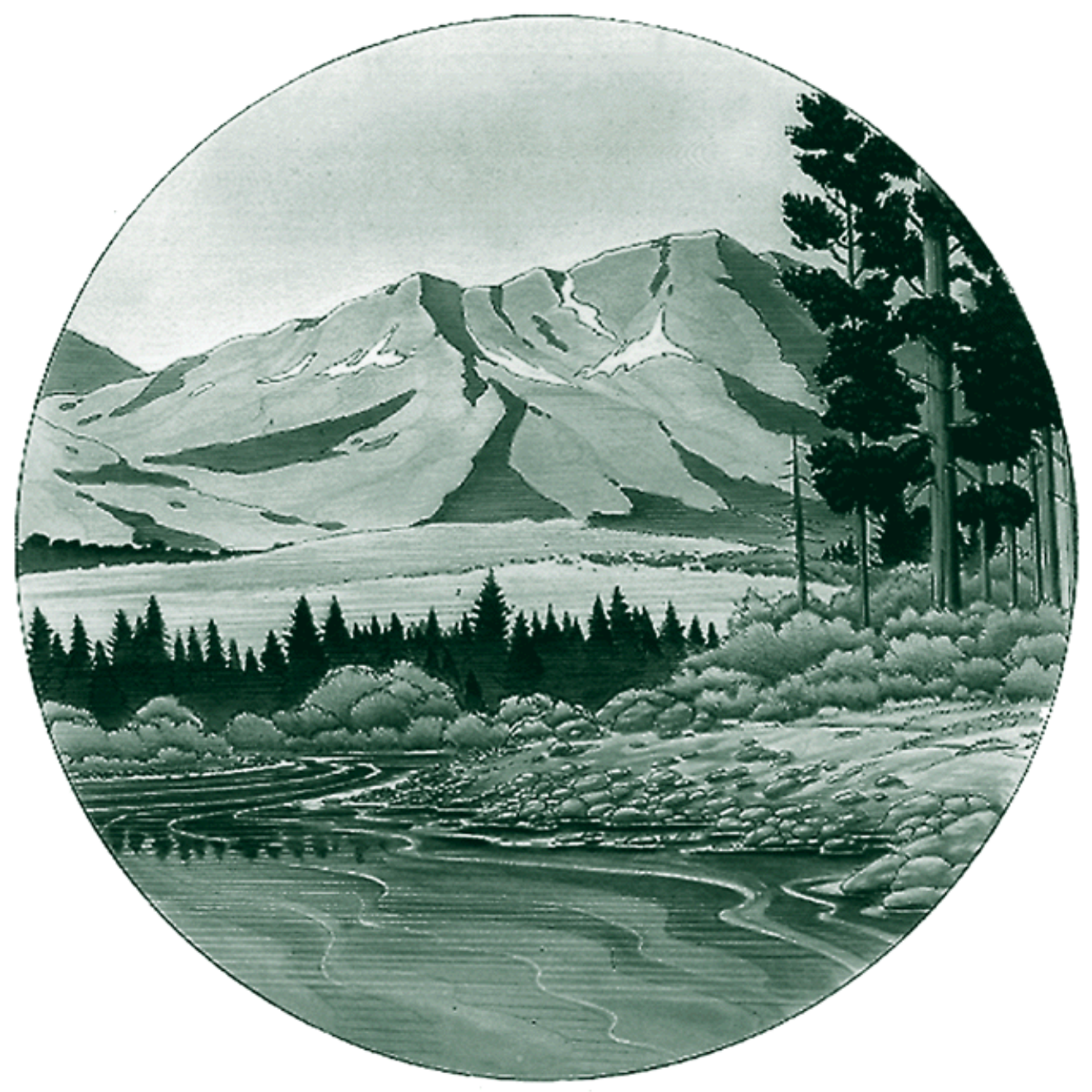

DOE/BP-25866-1 
This report was funded by the Bonneville Power Administration (BPA), U.S. Department of Energy, as part of BPA's program to protect, mitigate, and enhance fish and wildlife affected by the development and operation of hydroelectric facilities on the Columbia River and its tributaries. The views of this report are the author's and do not necessarily represent the views of BPA.

This document should be cited as follows:

Peterson, James T., S. P. Wollrab, U.S. Dept. of Agriculture Forest Service, 1999, An Analysis of Potential Stream Fish and Fish Habitat Monitoring Procedures for the Inland Northwest, Annual Report 1999 to Bonneville Power

Administration, Portland, OR, Contract No. 92AI25866, Project No. 92-032-00, 61 electronic pages (BPA Report DOE/BP-25866-1)

This report and other BPA Fish and Wildlife Publications are available on the Internet at:

\section{http://www.efw.bpa.gov/cgi-bin/efw/FW/publications.cgi}

For other information on electronic documents or other printed media, contact or write to:

Bonneville Power Administration

Environment, Fish and Wildlife Division

P.O. Box 3621

905 N.E. 11th Avenue

Portland, OR 97208-3621

Please include title, author, and DOE/BP number in the request. 


\title{
AN ANALYSIS OF POTENTIAL STREAM FISH AND FISH HABITAT MONITORING PROCEDURES FOR THE INLAND NORTHWEST
}

\author{
Prepared by: \\ James T. Peterson \\ and \\ Sherry P. Wollrab \\ U.S. Department of Agriculture Forest Service, \\ Rocky Mountain Research Station, Boise, Idaho
}

\author{
Prepared for: \\ U. S. Department of Energy \\ Bonneville Power Administration \\ Environment, Fish and Wildlife \\ P.O. Box 3621 \\ Portland, OR 97208-3621 \\ Project Number 92-032-00 \\ Contract Number 92AI25866
}

September 1999 


\section{TABLE OF CONTENTS}

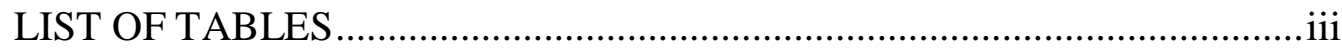

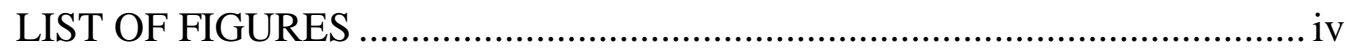

EXECUTIVE SUMMARY ……………………….................................. vi

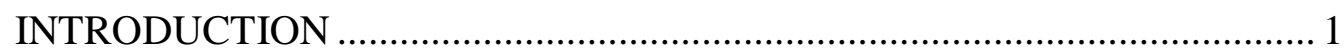

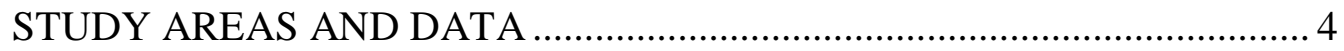

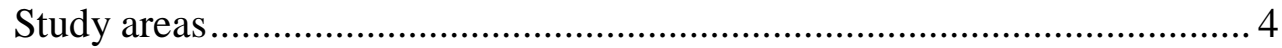

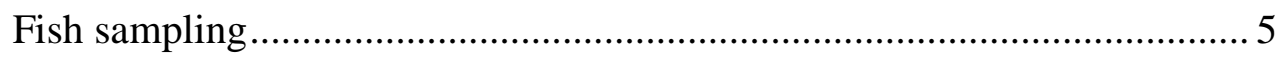

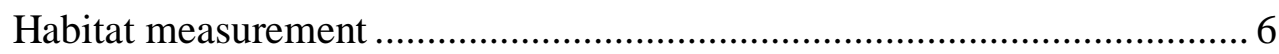

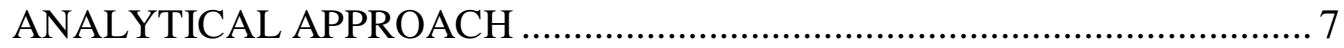

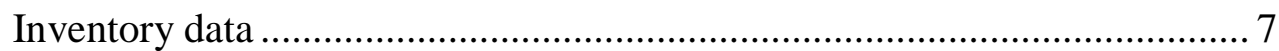

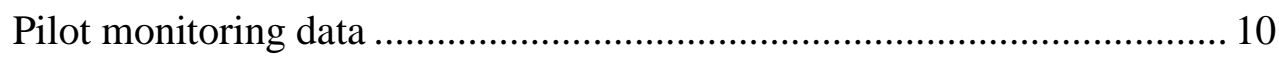

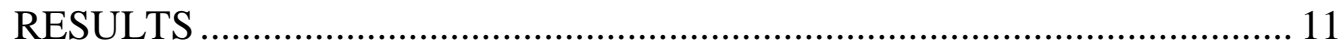

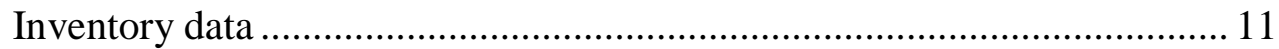

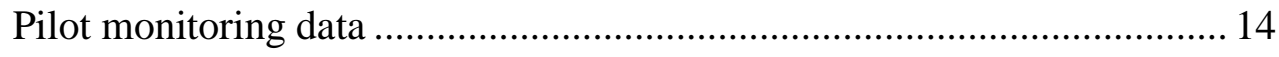

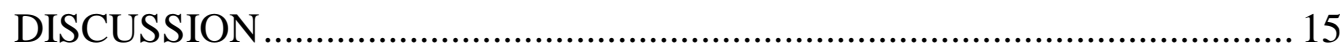

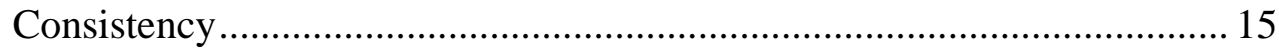

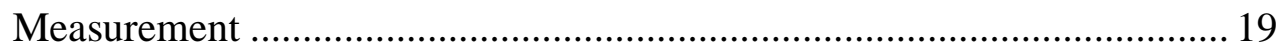

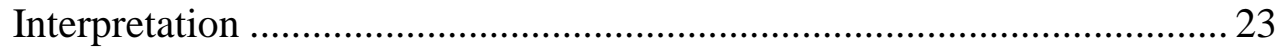

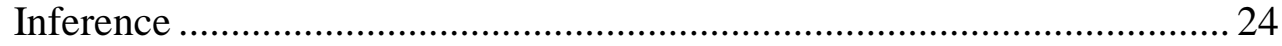

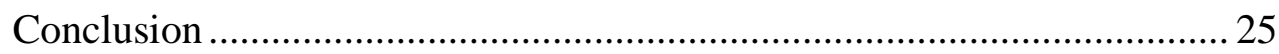

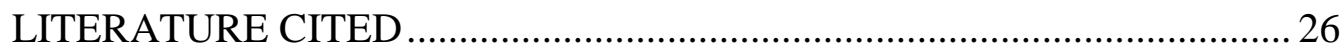




\section{LIST OF TABLES}

Table

1. Number of study sites and means and ranges of selected reach characteristics for the pilot monitoring study in the North Fork Boise Basin ...............................31

2. Summary of the characteristics of R1/R4 inventoried stream reaches.

3. Summary of the reach-specific factors examined for their potential effects of within-reach variance of fish species richness and salmonid density.

4. Pearson correlations among habitat characteristics and the within-reach coefficients of variation for species richness and salmonid density in inventoried stream reaches.

5. Summary of the reach-specific factors examined for their potential effects on within-reach variance of habitat characteristics.

6. Pearson correlations among total length, mean channel width, number of channel units sampled, and within-reach coefficients of variation for selected habitat characteristics of inventoried stream reaches

7. Median and range of the number of sub-reaches required for $20 \%$ precision (with $95 \%$ confidence) for selected habitat characteristics of inventoried stream reaches.

8. Pearson correlations among habitat characteristics of inventoried stream reaches after partialling-out the effect of stream width

9. Loadings of the first 4 principal components from an analysis of inventoried stream reach habitat characteristics after partialling-out the effect of stream width

10. The mean and range of the coefficients of variation of fish and fish habitat measurements from previous studies. 


\section{LIST OF FIGURES}

Figure

1. The location of inventoried stream channels and the North Fork Boise River Basin 38

2. The distribution of measured channel gradient for inventoried stream reaches 39

3. The distributions of the percent of channel units that were sampled for fish, the slow habitat type fish-sampling bias, the percent of channel units sub-sampled for habitat, and the slow habitat type sub-sampling bias

4. Scatterplot matrix of area sampled, mean depth of sampled channel units, stream temperature during sampling, number of channel units sampled, and the within-reach coefficients of variation for species richness and salmonid density in inventoried stream reaches

5. The median within-reach coefficients of variation of species richness and salmonid density, by parent geology and reach type, for inventoried stream reaches

6. Scatterplot matrix of the total length, mean width, number channel units measured, and the within-reach coefficients of variation of selected habitat characteristics for inventoried stream reaches.

7. The median within-reach coefficients of variation of wood frequency, pool frequency, percent undercut bank, and percent stable banks for inventoried stream reaches.

8. The median within-reach coefficients of variation of mean pool depth, percent surface fines, and width-to-depth ratio, by parent geology and reach type, for inventoried stream reaches

9. The frequency distributions of elevation, valley slope, soil erosion coefficient, and surface erosion hazard for 6th code watersheds in the Interior Columbia River Basin

10. The frequency distributions of management cluster type and geometric mean road density classes for 6th code watersheds in the interior Columbia River Basin 


\section{LIST OF FIGURES}

Figure

11. Mean species richness and bull and brook trout densities in streams in unburned-unlogged, burned-unlogged, and burned-logged catchments 48

12. The mean differences between streams in unburned-unlogged catchments and streams in burned-unlogged and burned-logged catchments for species richness and bull and brook trout densities

13. Mean wood frequency, pool frequency, and width-to-depth ratios of streams in unburned-unlogged, burned-unlogged, and burned-logged catchments.....

14. The mean differences between streams in unburned-unlogged catchments and streams in burned-unlogged, and burned-logged catchments for wood and pool frequency and width-to-depth ratio

15. The distributions of wood frequency, undercut banks, stable banks, width-todepth ratio, and mean pool frequency for natural condition stream reaches in the Salmon River Basin, Idaho 


\section{EXECUTIVE SUMMARY}

Natural resource managers in the Inland Northwest need tools for assessing the success or failure of conservation policies and the impacts of management actions on fish and fish habitats. Effectiveness monitoring is one such potential tool, but there are currently no established monitoring protocols. Since 1991, U.S. Forest Service biologists have used the standardized R1/R4 inventory procedures to measure fish and fish habitats on agency lands throughout the Intermountain West. The widespread use and acceptance of these standardized procedures and the large amount of data collected suggest that the R1/R4 procedures might provide the basis for an effectiveness monitoring protocol. Using fish and fish habitat data collected by Forest Service biologists, we assessed the efficacy of the R1/R4 procedures for monitoring stream fish and fish habitats.

The results of our analyses revealed several problems with the R1/R4 inventory procedures that would significantly reduce their usefulness as monitoring tools.

- Standardized sampling procedures were not applied consistently across Forest Service districts or within districts, across years. These inconsistencies could affect the quality of effectiveness monitoring data and impede the ability to detect change, limit valid comparisons across space and time, and introduce systematic bias into the data.

- Fish sampling and fish habitat measurement procedures were subjective, biased, and inadequate for estimating fish populations and characterizing fish habitat. Monitoring protocols that use these procedures would likely fail to detect significant changes or, worse, could indicate false changes in fish or fish habitats. 
- Specified quality assurance- quality control measures were not followed, which could significantly affect monitoring data quality and would reduce the ability to detect significant changes in fish or fish habitats.

- There are currently no means to interpret the R1/R4 fish habitat data. Thus, monitoring protocols that collect similar data would be unable assess the biological significance of habitat changes.

- Inventory reach selection was based on district-level needs and was significantly biased toward high-elevation, low-use areas. Monitor protocols that employ similar reach selection procedures would generate data that might not be useful for making regional assessments of fish and fish habitat.

These numerous and intractable problems suggest that the R1/R4 procedures should not be used for monitoring and that new procedures should be developed. Additionally, these problems also affected the quality of inventory data. Consequently, we believe that that the current R1/R4 inventory data may be inadequate to use as baselines for future monitoring efforts. 


\section{Introduction}

Recent concerns over the rapid declines of native stream-fish populations in the Inland Northwest have prompted the USDA Forest Service to institute interim land management practices intended to stop further declines in fish habitat quality and protect existing high quality habitat (USDA FS and USDI BLM 1995; NMFS 1998). These interim policies (commonly referred to as PACFISH and INFISH) will eventually be replaced by long-term management strategies for the protection and restoration of fish producing watersheds. Assessing the success of these interim policies and the effectiveness of alternative long-term management strategies is crucial. Failure to correctly identify the factors important for fish survival and reproduction or important land management effects could lead to further declines in these fish populations and the waste of scarce management resources. Consequently, natural resource managers in the Inland Northwest need tools for assessing the success or failure of these and other management actions.

Previous studies in the Inland Northwest have used effectiveness monitoring to assess whether management actions had the desired effect on stream fish and fish habitat (e.g., Platts and Nelson 1985). In general, effectiveness monitoring is the repeated measurement of some variable or set of variables over time with the expressed purpose of detecting a change that can be attributed to a specified management action (MacDonald et al. 1991). It is this purpose that makes effectiveness monitoring a potential tool for assessing the effects of management actions. In terms of it's application (e.g., sampling design, methods), effectiveness monitoring primarily differs from other types of biological assessments, such as inventories and surveys, by its temporal extent (i.e., repeated measurements taken over time) (Thompson et al. 1998). Thus, existing survey or inventory protocols could provide the basis for developing an effectiveness 
monitoring protocol. There are, however, a few critical features that survey or inventory protocols should posses to be useful for monitoring.

Consistency is one of the most important aspects of a monitoring protocol (Schreuder and Czaplewski 1993). Sampling procedures that cannot be consistently applied across space (e.g., among sites) and time can (1) affect data quality and impede the ability to detect change, (2) limit comparisons across space and time, and (3) introduce systematic bias into the data. Monitoring protocols should also include objective, repeatable, and precise measurement procedures (Thompson et al. 1998). The ability to detect changes or trends is directly influenced by data quality and quantity. Monitoring protocols that use inadequate or biased sampling methods may fail to detect significant changes or may indicate false changes (Thompson et al 1998). Similarly, the collection of an insufficient number of samples may fail to detect significant impacts (MacDonald et al. 1991), wasting valuable management resources (e.g., funds) and potentially damaging natural resources (e.g., fish populations).

Another important feature of a useful monitoring protocol is the interpretability of the data. A monitoring protocol can be designed and implemented to ensure the ability to statistically detect changes. However, if the data are not interpretable, the biological significance of a change can only be inferred (Bode and Novak 1995). For example, a statistically significant water temperature increase would have greater biological significance for coldwater fishes in a stream that is near the upper limit of their thermal tolerance when compared to a stream that is much cooler. It would be preferable from both a biological and legal standpoint to be able to assess biologically and statistically significant changes when monitoring (Adler 1995). Thus, fish and fish habitat monitoring protocols should include the collection of data that are readily interpretable. 
Since 1991, Forest Service biologists in the Northern and Intermountain Regions have used the R1/R4 fish and fish habitat inventory (or similar) procedures (Overton et al. 1997) to collect fish and fish habitat data for a wide variety of purposes ranging from baseline data collection to impact assessment. Although sampling objectives may have varied, the R1/R4 procedures were designed to ensure that fish and habitat data were collected in a standardized manner, which is an important feature of future effectiveness monitoring protocols. The R1/R4 procedures also have been used to develop reference conditions for assessing the relative quality of fish habitat (Overton et al. 1995), for watershed analysis (Overton et al. draft report), and to investigate the influence of wildfire and salvage logging on stream fish and fish habitats during a pilot monitoring study (Burton and Thornton 1995). The widespread use (and acceptance) of the R1/R4 standardized procedures and the large quantity of potential baseline information available suggest that these procedures may be a logical starting point for developing an effectiveness monitoring protocol.

The inventory data collected with the R1/R4 protocols also constitute a significant portion of information on stream fish and fish habitats on Forest Service lands in the Inland Northwest. Hence, these data may be useful as baselines for future effectiveness monitoring. The quality of baseline data, however, will significantly affect future evaluations of management strategies. Additionally, inventoried reaches were chosen for a wide variety of purposes and thus, the data may not produce the same result as a probabilistic or systematic sample. Inferences made with baseline data depend, in part, on how well the surveyed streams represent those on Forest Service lands (i.e., are they representative). Baseline data that do not properly depict streams typical of those on Forest Service lands will prevent valid extrapolation of the baseline data for future assessments of regional policies (e.g., PACFISH). To avoid these and other 
problems, any monitoring or inventory protocols should be thoroughly evaluated before they are used as representative baseline conditions for future monitoring efforts.

Because the R1/R4 approach may be widely adopted, we reviewed several recent applications with the goal of evaluating the potential utility of these techniques for monitoring. Our study objectives were to: (1) to examined the adequacy of R1/R4 inventory data for describing the current (i.e., baseline) condition of fish and fish habitats on Forest Service lands;

(2) examine the adequacy of the R1/R4 and similar inventory procedures for monitoring stream fish and fish habitats; (3) identify potentially significant problems and; (3) provide recommendations for developing and refining future monitoring protocols.

\section{Study Areas and Data}

We considered two recent applications of the R1/R4 methodology, one intended for inventory and the second for monitoring. In both applications, trained personnel collected fish and fish habitat data with standardized protocols from various streams types. Assuming that future monitoring efforts will be conducted under similar circumstances, we considered these data representative of monitoring data that would likely be collected using these procedures. Thus, an examination of these data should provide insight into the usefulness of the R1/R4 (or similar) procedures for monitoring.

\section{$\underline{\text { Study Areas }}$}

Inventory data.- Stream fishes and fish habitats were inventoried by Forest Service biologists in Regions 1 and 4 from 1991- 96. Stream and reach selection was not regionally coordinated and depended upon the needs of individual Districts and Forests. However, most inventoried stream reaches were located in Central and Southern Idaho and Western Montana (Figure 1), with the majority in the Salmon River Basin, Idaho. 
Pilot monitoring data.- A pilot monitoring study (Burton and Thornton 1995) was initiated after a 1994 wildfire burned over 180 thousand acres in the North Fork Boise River basin (Figure 1). The purpose of the study was to examine the effects of wildfire and salvage logging on bull trout (Salvelinus confluentus) and trout habitat, with an emphasis on stream temperature and sediment. Study reaches were located in 34 streams and encompassed 3 catchment disturbance types unburned-unlogged, burned-unlogged, and burned-logged (Table 1). All disturbance types had both lightly and heavily roaded sections.

\section{Fish sampling}

Inventory data.- In the R1/R4 inventoried streams, fish sampling was conducted by snorkeling during daylight hours in conjunction with the habitat measurements (below). The fish sampling techniques are described in Thurow (1994) and are briefly reviewed here. Water temperature was measured prior to sampling. All fish sampling began at the downstream end of each reach and proceeded upstream. Fishes were sampled in systematically selected channel units that were deep enough to submerge a diver's mask. Channel unit selection procedures varied among reaches and depended upon the decisions of Forest biologists. Beginning at the downstream end of each channel unit, 1-2 divers swam upstream, counted each fish, and identified salmonids to species.

Pilot monitoring data.- During the pilot monitoring project, fishes were collected with a backpack electrofisher and standardized 3-pass procedure with each pass starting at the downstream end of a reach and proceeding upstream. Salmon and trout were identified to species and the presence of other species was also recorded. 


\section{$\underline{\text { Physical Habitat Measurements }}$}

Physical habitat characteristics of both the inventoried and pilot monitoring reaches were measured or estimated using the standard R1/R4 inventory procedures (with the exception of fine sediment measurement, below). These are thoroughly described in Overton et al. (1997) and are briefly reviewed here. All streams were surveyed during summer baseflows. Prior to each survey, descriptions of the location of each reach (e.g., the names of up and downstream tributaries) were recorded and stream channel gradient was estimated from a 7.5-minute topographic map. Reach-type was also identified using the Rosgen (1985) classification system. Surveys began at the downstream end of each reach. Working upstream, individual channel units were identified (i.e., type) and length, wetted width, and average depth were measured. Large pieces of wood in each channel unit were also counted. The length, stability, and amount undercut of each bank adjacent to individual channel units were visually estimated. The percentage of the streambed composed of fine substrate (particles $>6 \mathrm{~mm}$ diameter) was also visually estimated in the inventoried streams. In some inventoried streams, measurements were only made in a sub-sample of the channel units, the selection of which depended upon the decisions of Forest biologists.

Pilot monitoring substrate measurement.- In contrast to the R1/R4 inventory, substrate measurement procedures varied among years and locations during the pilot monitoring study. Wolman (1954) Pebble Counts were collected at 128 sites in 1994-1996. The percentage of the streambed composed of fine substrate was visually estimated at 4 sites in 1994 and a grid-based substrate measurement procedure was used at 18 sites in both 1995 and 1996. In addition, VSTAR methods (for estimation of depth of fine substrate in pools, Lisle 1992) were used at the same locations and years as the grid method. Summary substrate variables also included 
calculated fines and spawning fines, which were estimates of the percentage of the streambed containing sediment particles with diameters $<6 \mathrm{~mm}$ and $<2.5 \mathrm{in}$, respectively.

\section{Analytical Approach}

The objective of effectiveness monitoring is to detect a change that can be attributed to a management action (McDonald et al. 1991). The ability to statistically detect a change depends upon the quality of the data (Cliff 1987). High variance is one factor that influences the ability to statistically detect a change (Gold 1969) and can only be overcome by increasing sample size and/ or collecting samples in a manner that minimizes variance (Snedecor and Cochran 1967, Sokal and Rohlf 1981). Sampling bias can also affect data quality by obfuscating significant changes or by indicating false changes (Thompson et al. 1989). Because data quality can significantly affect effectiveness monitoring, we focused our analysis on the most likely influences on data quality, such as measurement variance, potential sources of variance, and sample size requirements.

Inventory data.- We limited our analyses of the fish data to species richness (i.e., total number) and salmonid density, across species, because the species composition differed greatly among sites. These metrics are generally less variable than density estimates for individual species (Peterson and Rabeni 1995) and should therefore, be considered best-case scenarios for variance and sample size estimates. We also limited our analyses to the habitat features that were identified in the PACFISH interim riparian management objectives (RMO) as being significant to anadromous fish survival and reproduction (USDA FS and USDI BLM 1995). These included pool and large woody debris frequency, percent bank stability and undercut banks, and width-to-depth ratios. In addition, we included mean scour pool depth and surface fines in our analyses. 
Normality of the distribution of all fish and habitat data were assessed using Lilliefor's test (Lilliefor 1967). Significantly non-normal data $(\mathrm{P}<0.05)$ were natural $\log (\ln )$ transformed and reexamined.

The R1/R4 inventory procedures did not have predefined or standardized units-of-effort. As a result, sampling effort (e.g., reach length) and the number and types of channel units varied considerably among inventoried reaches (see results), which made it impossible to identify a common a unit-of-effort with which to examine within-reach variance. To provide a certain degree of consistency, we defined a unit-of-effort as a continuous stream section approximately 24 average channel widths long, which was similar to established stream monitoring protocols (e.g., EMAP: Overton et al. 1990). Inventoried reaches were separated into these standardized units by summing the length of adjacent channel units (starting at the downstream end of the reach) until the required reach length was realized. The process was then repeated for the remaining upstream channel units until each reach was separated into a series of sub-reaches. The sub-reaches were then treated as reach-specific 'replicates' for the analysis of within-reach variance and sample size estimation (below).

Preliminary analyses of the R1/R4 inventory data indicated substantial heterogeneity of variance among reaches that could not be remedied via data transformation. Consequently, we were unable to examine the variability of fish or habitat measures with traditional statistical methods, such as a model II analysis of variance. To examine potential sources of within-reach variance, we estimated the coefficients of variation $(\mathrm{CV}=$ standard deviation/mean) of the fish and habitat measurements for each reach. Pairwise Pearson correlations were then run among the reach-specific fish species richness and density CVs, the habitat variable CVs, and various reach-specific factors that may affect variance, such as the reach length and the number of channel-units sampled. 
The utility of a fish or habitat sampling protocol depends, in part, upon the ability to precisely characterize each reach. The number of sub-reaches $(N)$ that need to be sampled for a desired level of precision $(L)$, expressed as a percentage of the mean, were estimated as:

$$
\mathrm{N}=\left(\mathrm{t}^{2} \mathrm{CV}^{2}\right) / \mathrm{L}^{2}
$$

where $C V$ is the within-reach coefficient of variation for a fish or habitat measurement and $t$ is a constant that varies with confidence level (Snedecor and Cochran 1967). We estimated the number of sub-reaches needed to achieve $20 \%$ precision (i.e., $+/-20 \%$ of the 'true' mean) at the $95 \%$ confidence level $(t=1.96)$ because it is considered the most realistically attainable for stream fish estimates (Peterson and Rabeni 1995).

Highly correlated stream habitat characteristics are, presumably, created or maintained by similar processes (e.g., scour). Consequently, these characteristics would provide redundant information in a monitoring protocol because they are measures of the same underlying processes (or changes therein). Habitat characteristics (e.g., pool frequency) are also influenced by stream size (Gordon et al. 1992). Thus, correlations among habitat variables would probably reflect stream size effects, obfuscating the effects of underlying processes. To minimize (i.e., partial-out) the influence of stream size, we regressed average width on each habitat variable and calculated the residuals. The relationship among habitat characteristics, independent of stream width, was then examined by running pairwise Pearson correlations among the habitat variablespecific residuals. Principal component analysis (PCA) was then performed on the correlation matrix to evaluate redundancy.

To assess the representativeness of the inventoried streams, we assumed that watershedlevel features (e.g., valley physiography and land-use) influenced stream habitat characteristics. Thus, the representativeness of surveyed streams, was indirectly assessed by comparing the landscape characteristics of 6th code hydrologic units (watersheds) containing inventoried 
streams to those with at least $75 \%$ Forest Service ownership in the interior Columbia River Basin. Landscape data were obtained from the Forest Service Interior Columbia Basin Ecosystem Management Project (ICBEMP) (Jensen et al. 1997).

Pilot monitoring data.- Only six variables were collected consistently during the pre- and post-burn periods. The variables we examined included fish species richness (i.e., total number), bull and brook trout (S. fontinalis) density, pool and large woody debris frequency, and width-todepth ratio.

The number of monitoring sites varied among years and disturbance types (see results) and only reach summary data (i.e., means) were available for the pre-burn period (1994). The analyses were therefore, limited to an examination of the change in mean fish and habitat characteristics for each disturbance type, across streams. We assumed that changes in characteristics of streams in the burned-unlogged and burned-logged catchments would be due to a combination of wildfire, salvage logging activities (only in burned-logged), and natural processes, whereas stream changes in unburned-unlogged catchments would only be due to natural processes. Consequently, we estimated the change in fish and fish habitat due to wildfire and salvage logging as the difference between the average values of streams in unburnedunlogged catchments and streams in burned-unlogged and burned-logged catchments, respectively. Ninety-five percent confidence intervals of differences were calculated following Zar (1996) and were used to infer statistical significance. 


\section{Results}

Inventory data.- Fish and/or fish habitats were sampled in 1153 reaches on 313 streams. Total length and the number of channel units sampled varied considerably among reaches (Table 2). However, most reaches were in small, high elevation, high-gradient streams located on agency-administered lands. Thirty-eight reaches were reportedly resurveyed (i.e., same stream and reach ids in the same FS district), but the descriptions of reach locations did not match (between the two surveys) for $42 \%$ of these. Of those with identical location descriptions, reachtype differed between surveys for $23 \%$ and reach lengths, average widths, and number of channel units per reach varied an average of 282,86 , and $273 \%$ between surveys, respectively.

An examination of the data suggested substantial data quality problems. For example, $37 \%$ of the reaches had measured gradients outside the range defined for their reported reach type (Figure 2). Over 300 reaches were missing important information such as reach type, elevation, and gradient. Twenty-three percent of the fish samples were taken when water temperatures were lower than the minimum specified for the R1/R4 procedures (i.e., $9^{0} \mathrm{C}$ ). The habitat data had similar problems. For example, after correcting or eliminating over 800 obvious errors in the data (e.g., mean riffle depths $>0.75 \mathrm{~m}$ ), we found that approximately $7 \%$ of the reaches had mean low-gradient riffle depths that equaled or exceeded their scour pool depths. To minimize the influence of these and other errors, reaches with incomplete or highly suspect data were eliminated from further analyses.

Fishes were sampled in $45 \%$ of the inventoried reaches and in $25 \%$ of the channel units per reach, on average (Figure 3a). The total number of channel units sampled, however, ranged widely and fish sampling tended to be biased toward over-sampling 'slow' channel unit types, 
i.e., pools (Figure 3b). To obtain reasonable estimates of within-reach variance, we eliminated the data for reaches with less than 10 sampled channel units.

The CVs of species richness and salmonid density differed widely among reaches and ranged from 0.08-1.96 and 0.10-2.12, respectively. These differences, however, could not be attributed to any single source considered in this analysis (Table 3). Total area, number of channel units sampled, mean depth, and stream temperature were moderately negatively related to the CVs for species richness and salmonid density (Table 4 and Figure 4). There were also no substantial differences in the species richness and salmonid density CVs among streams with different parent geologies and reach-types (Figure 5). On average, species richness CVs were also less variable than salmonid density CVs. Required sample sizes to obtain $\pm 20 \%$ precision for species richness were, on the average, lower than salmonid density (6 and 40 sub-reaches, respectively).

In contrast to the fish data, habitat was measured in all of the inventoried reaches. However, the total number of channel units per reach was highly variable (Table 5) and in some reaches, habitat was only measured in a sub-sample of channel units (Figure 3c). The habitat sub-sampling procedure also tended to be biased toward over-sampling slow channel unit types (Figure 3d). To obtain reasonable estimates of within-reach variance, we eliminated the data for reaches with less than 20 channel units and less than 10 sub-reaches.

Similar to the fish data, the habitat variable CVs differed widely among reaches (range 0.06-1.97) and these differences generally could not be attributed to any single source considered in this analysis (Table 5). Stream width was positively related to the CVs for pool frequency and percent undercut bank and negatively related to the width-to-depth ratio CV (Table 6 and Figure 6). The number of channel units sampled per reach was negatively related to 
the CVs for pool frequency and percent undercut banks (i.e., fewer channel units $=$ higher variance). There were also no substantial differences in the habitat variable CVs among streams with different parent geologies and different reach-types (Figures 7 and 8). The median required sample sizes (i.e., number of sub-reaches) to obtain $\pm 20 \%$ precision also varied among habitat characteristics and were, on average, much lower than similar estimates for species richness and salmonid density. In general, bank stability and mean pool depth required the fewest sub-reaches, whereas pool frequency and undercut banks required the most (Table 7).

After partialling-out the effect of stream width, Pearson correlations of habitat characteristics suggested few strong relationships. Among these, pool frequency and percent undercut banks were positively correlated and mean pool depth and width-to-depth ratio were negatively correlated (Table 8). In contrast, bank stability was not substantially correlated with any of the habitat characteristics considered.

Principal component analysis reflected the correlation matrix. Measures of pool forming process (our interpretations), pool frequency and percent undercut banks, had the largest loadings on principal component 1 (Table 9), which accounted for $29.4 \%$ of the variance. Similarly, measures of stream cross-sectional area, width-to-depth ratio and mean pool depth, had the largest absolute loadings on principal component 2 , whereas bank stability and surface fines had the greatest loadings on component 3 .

Inventoried reaches were located in 168, 6th-code watersheds and represented, on average, $5.4 \%$ (range, $0.1-64.9 \%$ ) of the total length of perennial streams per watershed. Comparisons of these watersheds to those in 155 , 6th-code watersheds with at least $75 \%$ Forest Service ownership suggested a bias in reach selection. In general, inventoried streams tended to be disproportionately located in high elevation watersheds with low to moderate erosion 
potentials (Figure 9). These watersheds also tended to have disproportionately lower management impacts and lower road densities compared to those with at least 75\% Forest Service ownership in the interior Columbia River Basin (Figure 10).

Pilot monitoring data.- Fish and/or habitat samples were collected at 113 sites during the pilot monitoring study (Table 1). The number of sites varied among years and disturbance types. Pre- and post-burn data were collected at $18 \%$ of the sites and only $30 \%$ (6) of these were sampled each year; 3 burned-logged, 2 burned-unlogged, and 1 unburned-unlogged. The total number of sites also varied among disturbance-types with 25,15 , and 73 sites in the unburnedunlogged, burned-unlogged, burned-logged catchments, respectively. In addition, habitat reachlengths and the area of the fish sampling reaches differed substantially between pre- and postburn periods (Table 1).

The pilot monitoring data also varied substantially in quality. Data for some variables in some disturbance types and years were not collected. For example, fish were not collected in burned-unlogged sites during 1995 (Table 1) and stream temperature was only measured at ten sites during 1995. Wood and pool frequency estimates for the 1994-95 samples were also exceptionally high and were, on average, 591\% greater than PACFISH interim RMO thresholds (Table 1). Substrate sampling method and disturbance type and year were also confounded. For example, Wolman (1954) Pebble Counts were collected at 128 sites in 1994-1996, whereas the percentage of the streambed composed of fine substrate was visually estimated at 4 sites in 1994 and a grid-based substrate measurement procedure was used at 18 sites in 1995-1996. This confounding made it impossible to distinguish wildfire and salvage logging impacts from differences between sampling methods. 
Given the data, wildfire and salvage logging appeared to have had little impact on the fish communities during the study. Fish species richness and bull and brook trout densities remained relatively stable for most disturbance types with a couple of exceptions (Figure 11). Densities of bull and brook trout increased in streams in burned-unlogged and unburned-unlogged catchments, respectively. Species richness and bull and brook trout densities in streams in burned-unlogged and burned-unlogged catchments did not differ statistically from those in unburned-unlogged catchments. However, confidence intervals were relatively large and generally exceeded the mean differences by $200 \%$ (Figure 12), which suggested that species richness and fish density might have varied substantially among sites within each disturbance type.

In contrast to the fish, most habitat characteristics varied throughout the study. In general, wood and pool frequencies were highest in 1994-95 and declined in 96-97 (Figure 13). The width-to-depth ratios also decreased during the study. The habitat differences between streams in unburned-unlogged and burned-unlogged and burned-logged catchments were also not statistically significant (Figure 14). Similar to the fish, the habitat confidence intervals exceeded the mean differences by well over 500\%. Again, this suggested habitat characteristics differed substantially among sites within each disturbance type.

\section{Discussion}

Consistency.- One of the most significant problems we found during our investigation was the lack of consistency in the application of R1/R4 procedures during stream inventory and the pilot monitoring study. Most of these inconsistencies (outlined below) may have affected the usefulness of the R1/R4 inventory data for use as baselines for future monitoring and likely affected our ability to detect salvage logging effects with the monitoring data. 
The number of habitat measurements varied considerably among inventoried reaches due to a combination of sampling design and management decisions. Inventoried reaches were usually delineated by tributary junctions or changes in reach type, channel type, or management (Overton et al. 1997). Thus, reach lengths and the number of channel units therein, depended upon local geologic features or management boundaries rather than prespecified sample size requirements. The number of sub-sampled channel units, in contrast, was determined by the amount of manpower available. Variance is, in part, influenced by sample size (Sokal and Rolf 1981). Indeed, the negative correlation between number of channel units sampled and the CVs for fish species richness and density (Table 4) and pool frequency and undercut banks (Table 6) suggest that the heterogeneity of variance among inventoried reaches was due, in part, to differences in sample sizes. Collecting too few samples can lead to high variance and reduce the ability to detect a change. Future effectiveness monitoring protocols should include unambiguous sample size requirements.

During the pilot monitoring project, inconsistencies between the pre and post-burn sampling designs resulted in data that were inadequate for examining the effects of wildfire and salvage logging on stream fish and habitats. The objective during pre-burn was to gather as much information as possible on stream fish and habitats over a broad geographic area with limited manpower. Thus, samples were collected from a large number of relatively small sites (i.e., fewer measurements) (Table 1). To detect potential wildfire and salvage logging effects, it was assumed that site-level information should be more precise and hence, post-burn sites were much longer to accommodate a greater number of measurements (i.e., channel units). The combination of longer sites and manpower limitations also greatly reduced the number of post-burn study sites (Table 1). Consequently, the pre-burn sampling design (and data) would have been 
appropriate for examining changes in the average stream conditions in disturbance-type catchments because disturbance-type (i.e., across reach) measures were more precise. In contrast, the post-burn design would have been appropriate for examining the changes in the characteristics of individual sites in disturbance-type catchments because reach-specific measures were more precise. The use of both designs however, resulted in data that could not adequately address changes in average catchment characteristics (our analysis) or individual site characteristics. To avoid similar problems, future effectiveness monitoring protocols should maintain consistent sampling designs.

The fish data also may have been biased by the differences in reach sizes among inventoried reaches and among the pilot monitoring sites. The probability of detecting a fish species (and species richness) is a function of the number of vulnerable fishes and sampling efficiency (Bayley and Peterson 1998). The number of vulnerable fish, in turn, is a function of fish density and the size of the area sampled. Assuming identical sampling efficiencies (see Measurement section) and fish densities at each site, a smaller reach (area) would have fewer vulnerable fish and hence, lower probabilities of detecting a species when sampled (Peterson and Bayley 1998). This would introduce a systematic error into the data and could seriously bias apparent species richness and fish distribution patterns. For example, reaches sampled during the post-salvage period were, on the average, twice as large as pre-salvage reaches (Table 1). Therefore, the probability of detecting a species (species richness) was probably higher after the wildfire. Future monitoring protocols should avoid this type of systematic bias by attempting to maintain a consistent level-of-effort while sampling fish.

During the pilot monitoring study, data from a substrate measurement study were incorporated to increase the number of sites and geographic coverage during the pre-burn period. 
Consequently, substrate data were collected with different methods at different locations during different years, which resulted in the complete confounding of substrate-sampling method with disturbance type and year. This made it impossible to distinguish the potential effects of wildfire or salvage logging on stream sediment from differences between sampling methods. To avoid this type of confounding, future monitoring protocols should have procedures for incorporating new measurement techniques. For example, the new method could be calibrated by measuring the same area or feature (e.g., substrate size) with the old and new methods and developing a relationship (i.e., model). The previous data collected with the old method could then be adjusted using this model.

During monitoring, observed differences or changes are often the result of natural phenomena (McElravy et al. 1989). Potential confounding causes for an observed change should be investigated prior to concluding "anthropogenic effect" (Norris 1995). For example, consider a study that was designed to examine the effectiveness of a new management plan. Prior to the initiation of the plan, a manager collects baseline stream habitat data over several years. Unfortunately, the start of the management plan happens to coincide with a drought, which significantly lowers base-flow. The stream habitat measurements that year also indicate a significant decrease in average depth and pool frequency. The manager is then faced with the problem of determining what was the cause of the decrease in depth and pool frequency. To aid in these types of investigations, ancillary (explanatory) variables should be collected along with the fish and habitat data. For our example, the manager needs to know the relationship between discharge and depth and pool frequency. If discharge data were not collected, this relationship could not be investigated and the manager could not make any valid conclusions. Ancillary data were supposed to be collected as part of the R1/R4 inventory procedures. Unfortunately, they 
were collected inconsistently. For example, discharge and gradient were measured for only 39 and $74 \%$ of the reaches, respectively. Although this type of oversight may not seriously affect the quality of inventory data, future effectiveness monitoring protocols should have rigorous quality controls to ensure that these oversights do not occur.

The accuracy and precision of stream habitat measurements and, presumably, fish identification are affected by an observer's experience (Osborne et al. 1991). Most of the inventory and pilot monitoring data were collected and entered by temporary field-crews with varying levels of experience. To minimize the influence of inexperience, field crews were trained prior to sampling. Unfortunately, previous studies indicate even a moderate amount of training is generally not sufficient and thus, data collected by inexperienced field crews is often imprecise and can be biased (Ralph et al. 1991; Roper and Scarnecchia 1995). Although we were unable to determine the influence of crew inexperience with our data, the relatively high disagreement (37\%) between measured channel gradient and reach type (Figure 2) suggests that it may have been substantial. Experience also affected data recording and entry, and hence data quality. The $\mathrm{R} 1 / \mathrm{R} 4$ procedures outline data recording and entry proofing procedures to ensure data quality. Nonetheless, we found obvious errors in approximately $9 \%$ of the records. If these were included in an analysis, they would likely add variance and possibly bias to the data. To ensure consistent high quality data, future effectiveness monitoring protocols should implement rigorous quality assurance procedures.

Measurement.- The most significant problem we encountered during the study was inadequacy of the sampling methods specified by the R1/R4 inventory procedures. Because sampling methods also affect the quality of inventory data, the problems we've identified (below) probably influenced the usefulness of the R1/R4 inventory data as baselines for future 
monitoring. In addition, these measurement procedures may have reduced the ability to detect salvage logging effects with the pilot monitoring data.

The R1/R4 procedures use channel units as the basis for their stream habitat measurements. Previous studies of channel unit-based systems suggested that they were inadequate for monitoring because channel unit identification was subjective and imprecise and hence, the data were biased and highly variable (Roper and Scarnecchia 1996; Poole et al. 1997). We were unable to evaluate the adequacy of channel unit identifications using the inventory and pilot monitoring data because we had no measure of the true habitat structure. However, our examination of the data suggested patterns that were consistent with previous studies. For instance, reach-type (a somewhat subjective measure) differed between surveys for $23 \%$ of the resurveyed reaches. The extremely high pool frequencies for many of the pilot monitoring sites (Table 1) and the conflicting trends of decreased pool frequency and width-to-depth ratios (Figure 13) also suggest a significant measurement bias. To minimize the influence of observer bias and increase precision, the objectivity and repeatability of all sampling methods should be rigorously evaluated before adopting them for future effectiveness monitoring protocols.

Aside from the observer bias, the channel-unit habitat measurements were also inadequate for reach-level characterizations. Average width and depth of individual units were estimated by averaging readings from 3-4 locations, which is approximately half the number required to obtain $10 \%$ precision for the average depth of individual channel units in Missouri streams (J. Peterson, unpublished data). Because the habitat measurements were based on channel units, the total number of habitat measurements for a reach was partially determined by the length of individual channel units, which resulted in an unequal amount of sampling effort per reach. In several instances, an entire reach contained one channel unit and thus, the habitat 
data consisted of a single average width, depth, and fine substrate estimate with no estimate of precision. The size of individual channel units was also highly variable within reaches. Fifty-five percent of inventoried reaches had at least 1 channel unit shorter that $10 \mathrm{~m}$ and longer than $100 \mathrm{~m}$. These size differences made estimation of reach averages unnecessarily complex. For example, width-to-depth ratios for individual channel units had to be weighted by their lengths to obtain reach averages. Given our observations and those of other studies (cited above), we believe that channel-unit based habitat measurements are inadequate for monitoring stream habitats. Therefore, future effectiveness monitoring protocols should evaluate the efficacy of other habitat sampling methods.

Within-reach variation in this study differed greatly among reaches but was similar to the ranges reported for other stream studies (Table 10). High variance is generally overcome by increasing sample size and thus, the required number of samples for $20 \%$ precision ranged widely (Table 7). These highly variable sample size requirements suggest that universal sample sizes would be cost inefficient. For example, sample size requirements for estimating width-todepth ratios would require 17 sub-reaches (the maximum), which is 13 more than would be required for at least half of the streams (i.e., the median) (Table 7). The relationship between some reach characteristics and the within-reach CVs also suggest that universal sample size requirements could bias data because measurement error would be confounded with reach characteristics. For example, within-reach variation for pool frequency tended to be greater in wider streams (Table 6). A sampling protocol that included a fixed sample size based on average variance estimates (across stream sizes) would be insufficient for wider streams, resulting in systematically higher variances and the inability to detect change in the pool frequency of wide streams. The optimum monitoring design would allocate sampling effort according to the 
inherent variability of the observational units or strata (Peterson and Rabeni 1995), which can only be determined with empirical data. Consequently, we recommend that future effectiveness monitoring protocols include a pilot or implementation phase that allows for periodic evaluations of the data so that sampling strategies can be revised, if necessary.

Sampling efficiency can also significantly affect fish monitoring protocols. Fish sampling efficiency is influenced by the size and species of fish, as well as the physical habitat characteristics of the reach sampled (Dolloff et al. 1996; Hayes et al. 1996; Reynolds 1996 and references therein). Failure to account for differences in sampling efficiency introduces a systematic error or bias into the data, which can significantly affect estimates of fish density and distribution (Bayley and Dowling 1993). For example, a management action that increases stream temperature, but has no impact on actual fish density, may be perceived as beneficial to fish if more fish are collected due to increased sampling efficiency. Sampling efficiency also affects presence/absence and species richness data (discussed earlier) and can influence variance by affecting sampling error (Peterson and Rabeni 1995). Previous investigations have attempted reduce the influence of sampling bias by using a variety of maximum effort methods, such as multiple removal ("depletion" sampling) and mark and recapture methods. However, these techniques are also influenced by factors such as fish size, morphology, and behavior as well as the physical habitat characteristics of the area sampled (Buttiker 1992; Rodgers et al. 1992; Anderson 1995). To minimize the influence of fish sampling efficiency on data quality, future effectiveness monitoring protocols should incorporate fish sampling methods with known biases and apply them under circumstances in which catchability is reliable. 
Interpretation.- Currently, the only means to interpret stream fish habitat characteristics (or changes therein) are the PACFISH and INFISH interim RMOs (USDA FS and USDI BLM 1995; NMFS 1998). The RMOs are a set of criteria (i.e., threshold values) that were based on professional judgement and previous studies of salmonid life history requirements. They are interpreted such that if stream habitat characteristics meet or exceed the criteria, it is considered good habitat. However, an examination of the habitat characteristics of 235 natural condition streams in Salmon River Basin, Idaho (Overton et al. 1995) suggest that the PACFISH RMOs are inadequate for defining fish habitat quality. These streams were unaffected by anthropogenic impacts and should have presumably, met or exceeded the RMO thresholds. Yet, none of the streams met the undercut bank criteria, 95\% failed to meet the width-to-depth ratio criteria, and pool frequencies were significantly lower than the criteria (Figures 15b, d, and e). In addition, two PACFISH RMO variables, pool frequency and undercut banks, were highly correlated and provided redundant information, which could bias assessments (Hannaford and Resh 1995). Given our observations and those of previous investigations (Bisson et al. 1997 and references therein), we believe that the current PACFISH interim RMOs may be inadequate for determining the status of fish habitat and for assessing the biological significance of changes in habitat characteristics.

Another potential difficulty with the implementation of current protocols was the overreliance of habitat data as a means to evaluate the effects of land management practices on stream fishes. Fishes were only sampled in $45 \%$ of the inventoried reaches and in only $25 \%$ of the channel units per reach, on average. As discussed above, interpreting the biological significance of habitat change is difficult. Add to that difficulty the fact the land management actions can affect stream fishes through mechanisms other than physical habitat alteration (Poff 
and Ward 1989), and the evaluation of land management effects becomes even more difficult. To aid in the evaluation and interpretation of land management effects on fish, we recommend that future fish and fish habitat monitoring protocols place a greater emphasis on fish sampling than is currently done with the $\mathrm{R} 1 / \mathrm{R} 4$ procedures.

Inference.- Sampling design is another important aspect of a monitoring protocol (Schreuder and Czaplewski 1993). The ability to draw useful inferences from monitoring data is affected by site selection. Thus, monitoring protocols that use inappropriate or inconsistent sampling designs can severely limit the scope of inferences and render analyses invalid or inconclusive (Scheaffer et al. 1990).

The distribution of inventoried reaches across the region appeared to be biased towards higher elevation, lower impact areas (Figures 9 and 10). Inventoried reaches were chosen for a wide variety of purposes that depended on the needs of individual Districts or Forests. In most instances, habitat data were collected to provide baseline data on fish and fish habitats before the initiation of management activities. Thus, the reach selection bias was probably an artifact of management trends. Nonetheless, this bias could severely limit regional assessments of fish and fish habitats and reduce the ability to make informed, defensible management decisions. For example, an assessment of the influence of agency activities on salmonid populations across the region would be difficult using the current inventory data because any inferences would have to be restricted to higher elevation areas, where salmonid production is generally lower (Scarnecchia and Bergersen 1987), and to areas where land management impacts are probably minimal. Because of the influence of sample design on decision making, data collected for the varied needs of individual Districts or Forests would likely be inadequate for assessing regional or national goals. To ensure that data collected at the District of Forest level are adequate, 
sampling design and monitoring efforts should be coordinated at the appropriate level (e.g., regional goals $=$ regional coordination) .

Conclusion.- During our analyses, we found several potential difficulties in using the current (e.g., the R1/R4 inventory procedures) approaches to monitor fish and fish habitats. Existing procedures were not applied consistently across districts or even within districts across years, seriously affecting data quality. Fish and habitat sampling procedures were inadequate for characterizing streams, as were current guidelines for determining the status of fish habitat and for assessing the biological significance of changes. Finally, the present district-based sampling decisions (e.g., site selection, sampling effort) may make district-level data unsuitable for assessing regional objectives (e.g., PACFISH). Monitoring efforts will fail "if data are collected at the district level and are unusable for the intended policy objectives mandated at the regional and even national levels" (Lee and Bradshaw, draft manuscript). In this sense, regional monitoring efforts based on the current (or similar) system would likely fail. Our examination of the R1/R4 inventory data also suggests that it may be inadequate as baseline data for future monitoring efforts. These numerous problems indicate that simple modifications to the current system will not be sufficient. Rather, new procedures should be developed. Ill-conceived monitoring designs, however, can result in the collection of useless data. Worse, "a poorly performed survey [i.e., monitoring protocol] means the inertia of its imprecise results must be overcome before a legitimate survey can be conducted" (page xii, Thompson et al. 1998). To avoid these problems, we believe that natural resource managers should consider adopting an alternative approach to developing monitoring protocols. 


\section{Literature Cited}

Adler, R.W. 1995. Filling the gaps in water quality standards: legal perspectives on biocriteria. Pages 345-358. In Biological Assessment and Criteria. S. Davies and T.P. Simon, editors. Lewis, Boca Raton, Florida.

Anderson, C. 1995. Measuring and correcting for size selection in electrofishing mark-recapture experiments. Transactions of the American Fisheries Society 124:663-676.

Bayley, P.B. and D.C. Dowling. 1993. The effects of habitat in biasing fish abundance and species richness estimates when using various sampling methods in streams. Polskie Archiwum Hydrobiologii 40:5-14.

Bayley, P.B. and H.W. Li. 1993. Riverine fishes. Pages 251-280. In The Rivers Handbook, Volume 1. P. Calow and G. E. Petts, editors. Oxford Blackwell Scientific Publishers.

Bayley, P.B. and J.T. Peterson. 1998. Biases in estimating species richness of stream fish communities. 128th Annual Meeting of the American Fisheries Society. 23-27 August, Hartford, Connecticut.

Bisson, P., G.H. Reeves, R.E. Bilby, and R.J. Naiman. 1997. Watershed management and Pacific salmon: desired future conditions. Pages 447-474. In Pacific Salmon and Their Ecosystems. D. Stouder, P.A. Bisson, R.J. Naiman, and M.G. Duke, editors. Chapman and Hall, New York, New York.

Bode, R.W. and M.A. Novak. 1995. Development and application of biological impairment criteria for rivers and streams in New York State. Pages 97-107. In Biological Assessment and Criteria. S. Davies and T.P. Simon, editors. Lewis, Boca Raton, Florida.

Burton, T. and J. Thornton. 1995. Watershed and fisheries monitoring plan for the Boise River wildfire recovery project. Preliminary Report. U.S. Department of Agriculture, Forest Service, Boise National Forest, Idaho.

Buttiker, B. 1992. Electrofishing results corrected by selectivity functions in stock size estimates of brown trout (Salmo trutta L.) in brooks. Journal of Fish Biology 41:673-684.

Cliff, N. 1987. Analyzing Multivariate Data. Harcourt Brace Jovanovich, Chicago, Illinois.

Cochlan, W.P. 1981. Mark-recapture techniques of population size estimation. Dalhousie University, Halifax, Nova Scotia.

Cochran, W. and G. Cox. 1957. Experimental Designs. Wiley and Sons, New York, New York. 
Cowx, I.G. 1983. Review of the methods for estimating fish population size from survey removal data. Fisheries Management 14:67-82.

Dollof, A., J. Kershner, and R. Thurow. 1996. Underwater observation. Pages 533-553. In Fisheries Techniques, second edition. B.R. Murphy and D.W. Willis, editors. American Fisheries Society, Bethesda, Maryland.

Gold, D. 1969. Statistical tests and substantive significance. American Sociologist 4: 42-46.

Gordon, N.D., T.A. McMahon, and B.L. Finlayson. 1992. Stream Hydrology: An introduction for Ecologists. Wiley and Sons, West Sussex, England.

Hankin, D. G. and G. H. Reeves. 1988. Estimating total fish abundance and total habitat area in small streams based on visual estimation methods. Canadian Journal of Fisheries and Aquatic Sciences 45: 834-844.

Hannaford, M.J. and V.H. Resh. 1995. Variability in macroinvertebrate rapid-bioassessment surveys and habitat assessments in a northern California stream. Journal of the North American Benthological Society 14:430-439.

Hayes, D.B., C.P. Ferreri, and W.J. Taylor. 1996. Active capture methods. Pages 193-219. In Fisheries Techniques, second edition. B.R. Murphy and D.W. Willis, editors. American Fisheries Society, Bethesda, Maryland.

Jensen, M.E., I. Goodman, K. Brewer, T. Frost, and J. Nesser. 1997. Biophysical environments of the basin. Volume 1, Chapter 2. In An assessment of ecosystem components in the interior Columbia Basin and portions of the Klamath and Great Basins. General Technical Report PNW-GTR-405. U.S. Department of Agriculture, Forest Service, Pacific Northwest Research Station, Portland, Oregon.

Lee, D.C. and G.A. Bradshaw. Draft manuscript. Making Monitoring Work for Managers. Online at < http://www.icbemp.gov/spatial/lee_monitor/begin.html >.

Lilliefor, H. W. 1967. On the Kolomogorov-Smirnov test for normality with mean and variance unknown. Journal of the American Statistical Association 62: 399-402.

Lisle, T.E. and S. Hilton. 1992. The volume of fine sediment in pools: An index of sediment supply in gravel bed channels. Water Resources Research 31: 1107-1118. 
MacDonald, L.H., A. Smart, and R.C. Wissmar. 1991. Monitoring guidelines to evaluate the effects of forestry activities on streams in the Pacific Northwest and Alaska. Water division EPA/910/9-91-001, U.S. Environmental Protection Agency, Region 10, Seattle Washington.

McElravy, E.P., G.A. Lamberti, and V.H. Resh. 1989. Year-to-year variation in the aquatic macroinvertebrate fauna of a northern California stream. Journal of the North American Benthological Society 8:51-63.

National Marine Fisheries Service (NMFS). 1998. Biological opinion on land and resource management plans for National Forests and Bureau of Land Management Resource Areas in the Upper Columbia River basin and Snake River Basin Evolutionary Significant Units. NMFS Northwest Region, Seattle, Washington.

Norris, R.H. 1995. Biological monitoring: the dilemma of data analysis. Journal of the North American Benthological Society 14:440-450.

Osborne, L.L., and 13 co-authors. 1991. Stream habitat assessment programs in states of the AFS North Central Division. Fisheries 16:28-35.

Overton, C.K, J.D. McIntyre, R. Armstrong, S.L. Whitwell, and K.A. Duncan. 1995. Users guide to fish habitat: Descriptions that represent natural conditions in the Salmon River basin, Idaho. General Technical Report INT-GTR-345. U.S. Department of Agriculture, Forest Service, Intermountain Research Station, Ogden, Utah.

Overton, C.K, ., S.P. Wollrab, and M.A. Radko. Draft report. Watershed analysis approaches for Chinook salmon, Yankee Fork of the Salmon River, Idaho: an example. U.S. Department of Agriculture, Forest Service, Rocky Mountain Research Station, Boise, Idaho.

Overton, C.K., S.P. Wollrab, B.C. Roberts, and M.A. Radko. 1997. R1/R4 (Northern/ Intermountain Regions) fish and fish habitat standard inventory procedures handbook. General Technical Report INT-GTR-346. U.S. Department of Agriculture, Forest Service, Intermountain Research Station, Odgen, Utah.

Overton, W.S., D. White, D.L. Stevens Jr. 1990. Design Report for EMAP. EPA/600/3-91/053. U.S. Environmental Protection Agency, Corvallis, Oregon.

Peterson, J.T. and P.B. Bayley. 1998. The influence of sampling efficiency on analyses of species presence/absence in relation to habitat. 128th Annual Meeting of the American Fisheries Society. 23-27 August, Hartford, Connecticut. 
Peterson, J.T. and C.F. Rabeni. 1995. Optimizing sampling effort for sampling warmwater stream fish communities. North American Journal of Fisheries Management 15:528-541.

Platts, W.S. 1981. Stream inventory garbage in-reliable analysis out: only in fairy tales. Pages 75-84. In Acquisition and Utilization of Aquatic Habitat Inventory Information. N.B. Armantrout, editor. American Fisheries Society, Western Division, Bethesda, Maryland.

Platts, W.S. and R.L. Nelson. 1985. Impacts of rest-rotation grazing on stream banks in forested watersheds in Idaho. North American Journal of Fisheries Management 5:547-556.

Poff, N.L. and J.V. Ward. 1989. Implications of streamflow variability and predictability for lotic community structure: a regional analysis. Canadian Journal of Fisheries and Aquatic Sciences 46:1805-1817.

Poole, G.C., C.A. Frissell, and S.C. Ralph. 1997. In-stream habitat unit classification: inadequacies for monitoring and some consequences for management. Water Resources Bulletin 33:879-896.

Ralph, S.C., T. Cardoso, G.C. Poole, L.L. Conquest, and R.J. Naiman. 1991. Status and trends of instream habitats in forested lands of Washington: The Timber-Fish-Wildlife Ambient Monitoring Project. Biennial Progress Report, Center for Streamside Studies, University of Washington, Seattle, Washington.

Reynolds, J.B. 1996. Electrofishing. Pages 221-254. In Fisheries Techniques, second edition. B.R. Murphy and D.W. Willis, editors. American Fisheries Society, Bethesda, Maryland.

Reiser, D.W. 1988. Effects of two sediment size-classes on survival of steelhead and chinook salmon eggs. North American Journal of Fisheries Management 8(4):432-437.

Rodgers, J.D., M.F. Solazzi, S.L. Johnson, and M.A. Beckman. 1992. Comparison of three techniques to estimate juvenile coho salmon populations in small streams. North American Journal of Fisheries Management 12:79-86.

Roper, B.B. and D.L. Scarnecchia. 1995. Observer variability in classifying habitat types in stream surveys. North American Journal of Fisheries Management 15:49-53.

Rosgen, D.L. 1985. A stream classification system. Pages 91-95. In Riparian ecosystems and their management: reconciling conflicting uses. R.R. Johnson, C.D. Ziebell, D.R. Palton, P.F. Ffolliott, R.H. Hamre, editors. Proceedings of the First North American Riparian Conference. General Technical Report RM-120. U.S. Department of Agriculture, Forest Service, Rocky Mountain Forest and Range Experiment Station, Ft. Collins, Colorado. 
Scarnecchia, D.L. and E.P. Bergersen. 1987. Trout production and standing crop in Colorado's small streams, as related to environmental features. North American Journal of Fisheries Management 3:315-330.

Scheaffer, R.L., W. Mendenhall, and L. Ott. 1990. Elementary survey sampling, fourth edition. Kent Publishing, Boston, Massachusetts.

Schnute, J. 1983. A new approach to estimating populations by the removal method. Canadian Journal of Fisheries and Aquatic Sciences 40:2153-2169.

Schreuder H.T. and R.L. Czaplewski. 1993. Long-term strategy for the statistical design of a forest health monitoring system. Environmental Monitoring and Assessment 27:81-94.

Snedecor, W.S. and W.G. Cochran. 1967. Statistical Methods, sixth edition. Iowa State University Press, Ames, Iowa.

Sokal, R. and F. Rohlf. 1981. Biometry. W.H. Freeman, San Francisco, California.

Thompson, W.L., G.C. White, and C. Gowan. 1998. Monitoring Vertebrate Populations. Academic Press, San Diego, California.

Thurow, R.F. 1994. Underwater methods for study of salmonids in the Intermountain West. General Technical Report INT-GTR-307. U.S. Department of Agriculture, Forest Service, Intermountain Research Station, Odgen, Utah.

U.S. Department of Agriculture, Forest Service and U.S. Department of the Interior, Bureau of Land Management. 1995. Environmental assessment for the implementation of interim strategies for managing anadromous fish-producing watersheds in eastern Oregon and Washington, Idaho, and portions of California. Washington, D.C. [SS/X.A.1.3].

Wolman, M. G. 1954. A method of sampling coarse river-bed material. American Geophysical Union Transactions 35(6): 951-956.

Zar, J.H. 1996. Biostatistical Analysis, third edition. Prentice Hall, Upper Saddle River, New Jersey. 
Table 1. The number of study sites (in parenthesizes) and means and ranges of selected reach characteristics, by disturbance type, for pilot monitoring study in the North Fork Boise Basin. Missing data are represented by dashes. PACFISH riparian management objective (RMO) thresholds are shown for comparison.

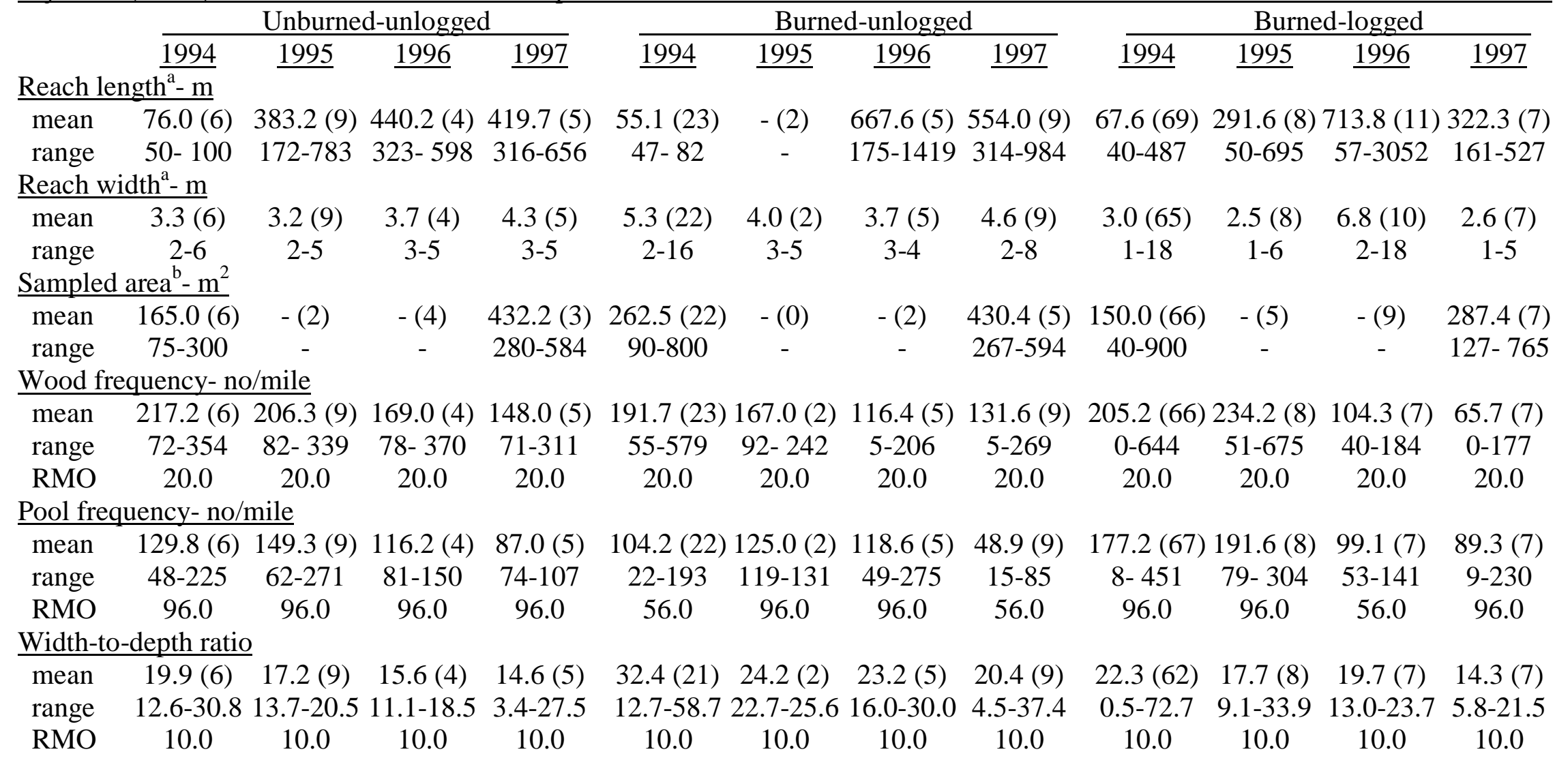

\footnotetext{
${ }^{\mathrm{a}}$ Only included habitat measurements.

${ }^{\mathrm{b}}$ Only included fish sampling.
} 
Table 2. Summary of the characteristics of R1/R4 inventoried stream reaches.

Mean

$\underline{\text { Range }}$

Elevation (m)

2118.6

$538-6960$

Channel gradient (\%)

3.74

$0.1-30.0$

Number of channel units per reach

61.1

$1-648$

Total reach length (m)

1763.3

$8-12236$

Average channel width (m)

5.94

$0.7-34.8$

Average depth (m)

0.29

$0.09-1.71$

Table 3. Summary of the reach-specific factors examined for their potential effects on withinreach variance of fish species richness and salmonid density, $\mathrm{N}=167$.

\begin{tabular}{lcc} 
& $\underline{\text { Mean }}$ & $\underline{\text { Range }}$ \\
Total area sampled $\left(\mathrm{m}^{2}\right)$ & 2437.2 & $84-15634$ \\
Mean depth of sampled units $(\mathrm{m})$ & 0.27 & $0.11-0.48$ \\
Mean stream temperature $\left({ }^{0} \mathrm{C}\right)$ & 12.4 & $9-21$ \\
Number of channel units sampled & 23.2 & $10-127$ \\
\hline
\end{tabular}


Table 4. Pearson correlations among total area sampled, mean depth, water temperature, number of channel units sampled, and the within-reach coefficients of variation (CV) for species richness and salmonid density in inventoried stream reaches.

\begin{tabular}{|c|c|c|c|c|c|}
\hline & $\begin{array}{c}\text { Area } \\
\text { sampled } \\
\end{array}$ & $\begin{array}{l}\text { Mean } \\
\underline{\text { depth }}\end{array}$ & $\begin{array}{c}\text { Mean } \\
\text { temperature } \\
\end{array}$ & $\begin{array}{l}\text { Number of } \\
\text { channel units } \\
\text { sampled }\end{array}$ & $\begin{array}{c}\mathrm{CV} \\
\text { Species } \\
\underline{\text { richness }} \\
\end{array}$ \\
\hline Mean depth of sampled units & 0.4118 & & & & \\
\hline Mean stream temperature & 0.1868 & -0.0048 & & & \\
\hline Number of channel units sampled & 0.1805 & -0.1790 & -0.0877 & & \\
\hline Species richness CV & -0.1352 & -0.2344 & -0.1165 & -0.2163 & \\
\hline Salmonid density CV & -0.0964 & -0.1605 & -0.1367 & -0.2548 & 0.7478 \\
\hline
\end{tabular}

Table 5. Summary of the reach-specific factors examined for their potential effects on withinreach variance of habitat characteristics, $\mathrm{N}=367$.

\begin{tabular}{lcc} 
& $\underline{\text { Mean }}$ & $\underline{\text { Range }}$ \\
Reach length (m) & 2110.9 & $212-9309$ \\
Mean channel width (m) & 7.97 & $1.49-24.4$ \\
Number of channel units sampled & 72.7 & $20-626$ \\
\hline
\end{tabular}


Table 6. Pearson correlations among total length, mean channel width, number channel units sampled, and the within-reach coefficients of variation $(\mathrm{CV})$ for selected habitat characteristics of inventoried stream reaches.

\begin{tabular}{|c|c|c|c|c|c|c|c|c|c|}
\hline \multirow[b]{2}{*}{$\underline{\text { Variable }}$} & \multirow[b]{2}{*}{$\begin{array}{l}\text { Reach } \\
\text { length }\end{array}$} & \multirow[b]{2}{*}{$\begin{array}{c}\text { Mean } \\
\text { channel } \\
\underline{\text { width }}\end{array}$} & \multirow[b]{2}{*}{$\begin{array}{c}\text { Number of } \\
\text { channel units } \\
\text { sampled }\end{array}$} & \multicolumn{6}{|c|}{ Coefficients of variation } \\
\hline & & & & $\begin{array}{c}\text { Wood } \\
\text { frequency }\end{array}$ & $\begin{array}{c}\text { Pool } \\
\text { frequency }\end{array}$ & $\begin{array}{l}\text { Percent } \\
\text { undercut } \\
\underline{\text { banks }}\end{array}$ & $\begin{array}{c}\text { Percent } \\
\text { stable } \\
\underline{\text { banks }}\end{array}$ & $\begin{array}{l}\text { Mean } \\
\text { pool } \\
\text { depth }\end{array}$ & $\begin{array}{l}\text { Percent } \\
\text { surface } \\
\underline{\text { fines }}\end{array}$ \\
\hline Mean channel width & 0.1887 & & & & & & & & \\
\hline No. channel units sampled & 0.5466 & -0.3376 & & & & & & & \\
\hline Wood frequency CV & -0.0086 & -0.0430 & 0.0439 & & & & & & \\
\hline Pool frequency CV & 0.0990 & 0.4497 & -0.3311 & 0.0435 & & & & & \\
\hline Percent undercut banks CV & 0.1127 & 0.2904 & -0.2173 & -0.0185 & 0.2548 & & & & \\
\hline Percent stable banks CV & 0.0411 & -0.0732 & 0.0294 & 0.0269 & 0.0932 & 0.0586 & & & \\
\hline Mean pool depth CV & 0.0870 & 0.0899 & 0.0466 & 0.0333 & 0.1031 & 0.1195 & 0.0073 & & \\
\hline Percent surface fines CV & -0.0221 & 0.1554 & -0.0363 & -0.0381 & 0.0310 & 0.0416 & 0.0020 & 0.0559 & \\
\hline Width-to-depth ratio CV & -0.0298 & -0.3008 & 0.0838 & 0.1076 & -0.1570 & 0.1635 & 0.0732 & 0.1959 & -0.0595 \\
\hline
\end{tabular}


Table 7. Median and range of the number of sub-reaches required for $20 \%$ precision (with $95 \%$ confidence) for selected habitat characteristics of inventoried stream reaches. Estimates are for natural-log transformed data.

\begin{tabular}{lcc}
\multicolumn{1}{c}{ Variable } & Median & $\underline{\text { Range }}$ \\
Wood frequency & 9 & $2-217$ \\
Pool frequency & 17 & $2-384$ \\
Percent undercut banks & 16 & $2-309$ \\
Percent stable banks & 2 & $2-129$ \\
Mean pool depth & 3 & $2-54$ \\
Percent surface fines & 4 & $2-297$ \\
Width-to-depth ratio & 4 & $2-17$
\end{tabular}

Table 8. Pearson correlations among habitat characteristics of inventoried stream reaches after partialling-out the effect of stream width.

$\underline{\text { Variable }}$

Pool frequency

Percent undercut banks

Percent stable banks

Mean pool depth

Percent surface fines ${ }^{1}$

Width-to-depth ratio

\begin{tabular}{|c|c|c|c|c|c|}
\hline $\begin{array}{c}\text { Wood } \\
\text { frequency }\end{array}$ & $\begin{array}{c}\begin{array}{c}\text { Pool } \\
\text { frequency }\end{array} \\
\end{array}$ & $\begin{array}{l}\text { Percent } \\
\text { undercut } \\
\underline{\text { banks }}\end{array}$ & $\begin{array}{l}\text { Percent } \\
\text { stable } \\
\underline{\text { banks }}\end{array}$ & $\begin{array}{c}\text { Mean } \\
\text { pool } \\
\text { depth }\end{array}$ & $\begin{array}{l}\text { Percent } \\
\text { surface } \\
\underline{\text { fines }}\end{array}$ \\
\hline 0.1560 & & & & & \\
\hline 0.2625 & 0.4518 & & & & \\
\hline 0.0381 & 0.1253 & 0.0521 & & & \\
\hline-0.1092 & -0.1875 & -0.0761 & 0.0069 & & \\
\hline 0.0044 & 0.2178 & 0.0114 & -0.1086 & -0.1558 & \\
\hline 0.0026 & -0.1959 & -0.2742 & -0.1665 & -0.5995 & 0.1882 \\
\hline
\end{tabular}


Table 9. Loadings of the first 4 principal components from an analysis of inventoried stream reach habitat characteristics after partialling-out the effect of stream width.

\begin{tabular}{lcccc} 
& $\underline{\mathrm{PC} 1}$ & $\underline{\mathrm{PC} 2}$ & $\underline{\mathrm{PC} 3}$ & $\underline{\mathrm{PC} 4}$ \\
Wood frequency & 0.3923 & 0.0315 & -0.3379 & -0.5680 \\
Pool frequency & 0.6126 & -0.0420 & 0.2278 & 0.2339 \\
Percent undercut banks & 0.5879 & -0.1882 & 0.0222 & -0.2138 \\
Percent stable banks & 0.1627 & -0.2078 & -0.5664 & 0.6975 \\
Mean pool depth & -0.2830 & -0.5889 & 0.2691 & -0.1053 \\
Percent surface fines & 0.2031 & 0.3174 & 0.6333 & 0.2805 \\
Width-to-depth ratio & $\underline{-0.1128}$ & $\underline{0.6864}$ & $\underline{-0.1979}$ & $\underline{-0.0270}$ \\
\% Variance explained & 29.4 & 24.5 & 15.0 & 13.5 \\
\hline
\end{tabular}


Table 10. The mean and range of coefficients of variation, expressed as a proportion, of fish and habitat measurements from previous studies.

$$
\text { Variable } \quad \underline{\text { Mean }} \text { Range }
$$

Fish

Idaho Fish and Game general parr monitoring database

$\begin{array}{lll}\text { Species richness } & 0.32 & 0.14-0.86 \\ \text { Salmonid density, across species } & 0.75 & 0.18-1.90\end{array}$

Hankin and Reeves (1988)

Coho salmon abundance $\quad 0.11$

Steelhead trout abundance $\quad 0.08$

Peterson and Rabeni (1995) ${ }^{1}$

Species richness $\quad 0.29$

$0.18-0.52$

Fish density, across species

0.32

$0.24-0.77$

Habitat

Platts (1981)

Mean depth $\quad 0.14$

Percent pool (pool frequency) $\quad 0.22$

Percent coarse fine sediment $\quad 0.51$

Peterson and Rabeni (in review) ${ }^{1}$

$\begin{array}{lll}\text { Mean depth } & 0.20 & 0.11-0.44 \\ \text { Woody debris } & 0.66 & 0.21-1.00 \\ \text { Percent sand and silt (fines) } & 0.65 & 0.19-0.92\end{array}$

${ }^{1}$ Estimates for channel unit-specific measurements. 


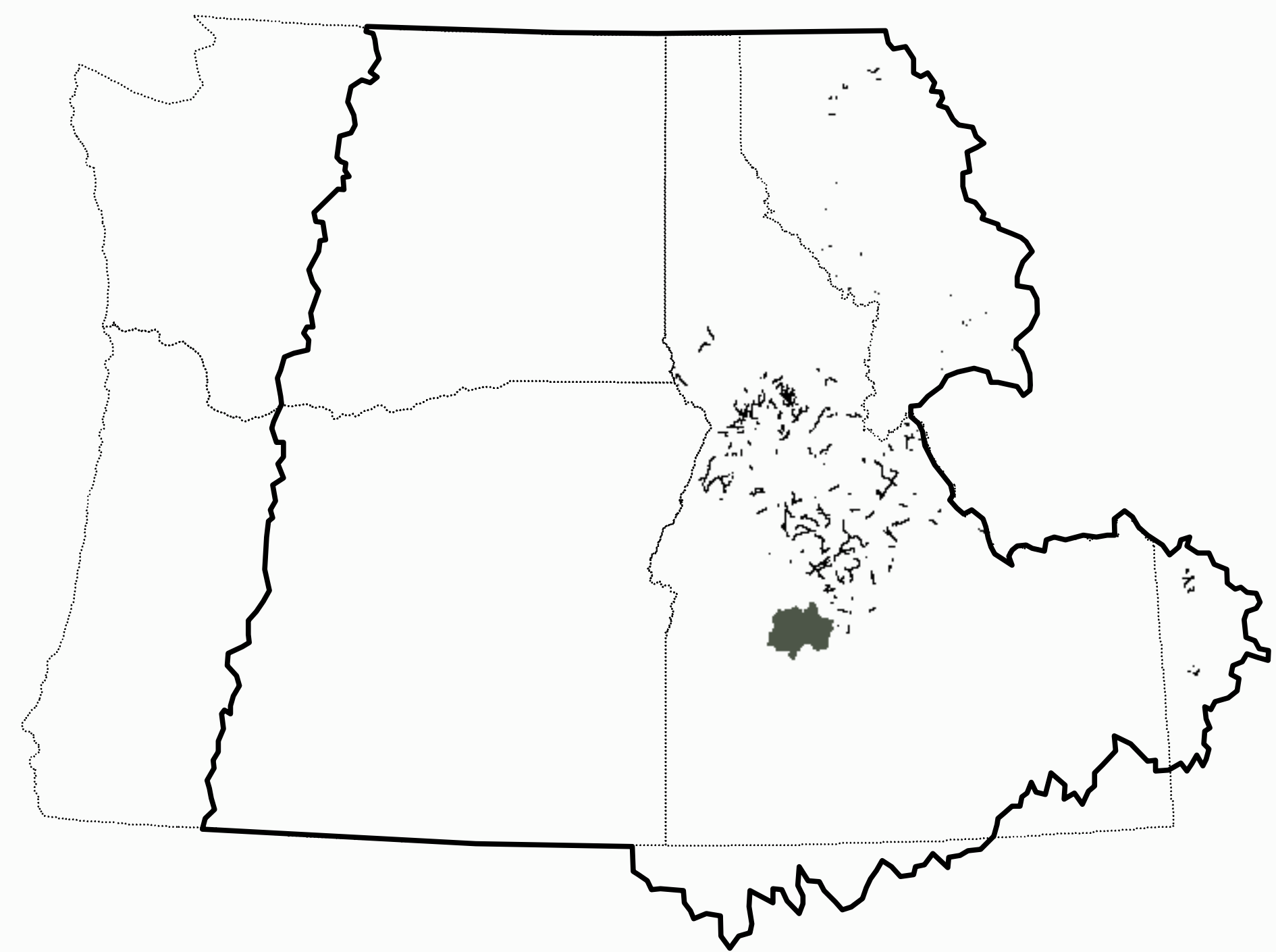

Figure 1. The location of inventoried stream channels (thin lines) and the North Fork Boise River Basin (shaded). The interior Columbia River Basin (bold outline) and state boundaries (broken line) are shown for reference. 


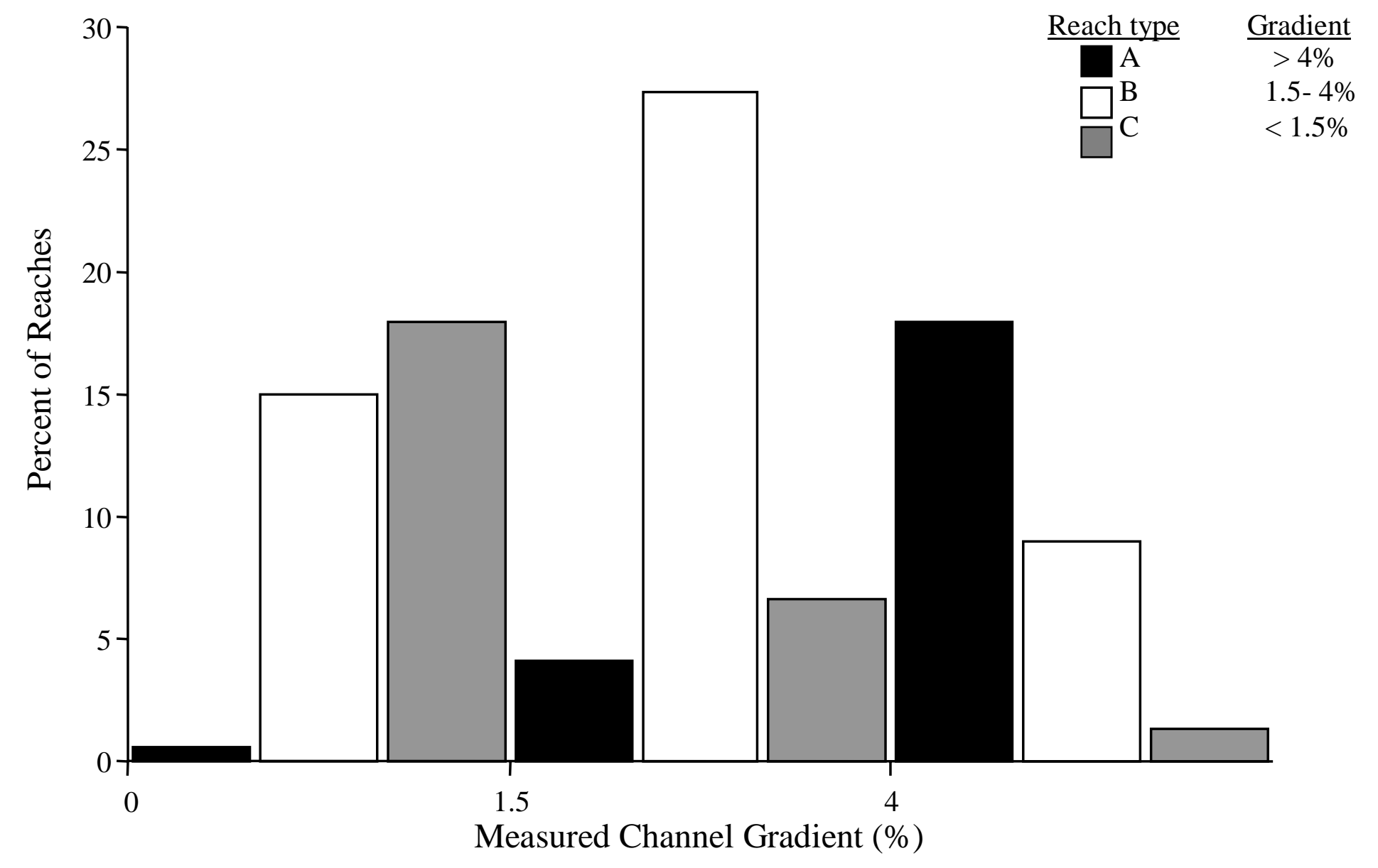

Figure 2. The distribution of measured channel gradient, by reach type, for inventoried stream reaches and reach-type gradients as defined in the R1/R4 inventory protocols (Overton et al. 1997). 
a.

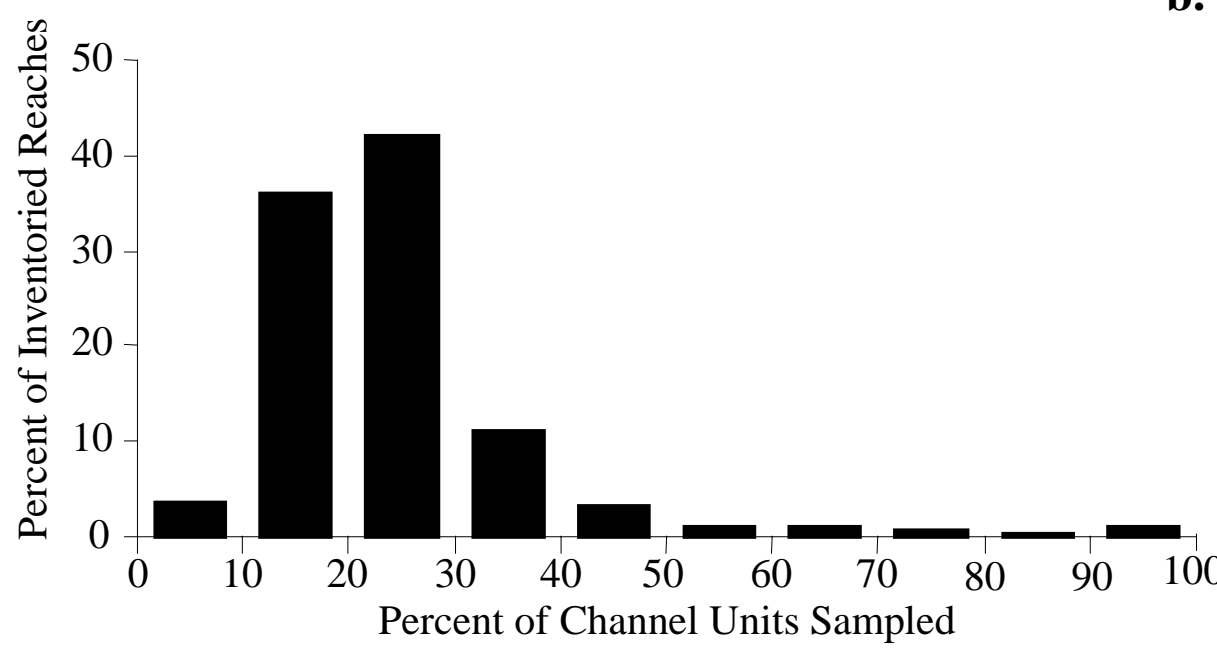

b.

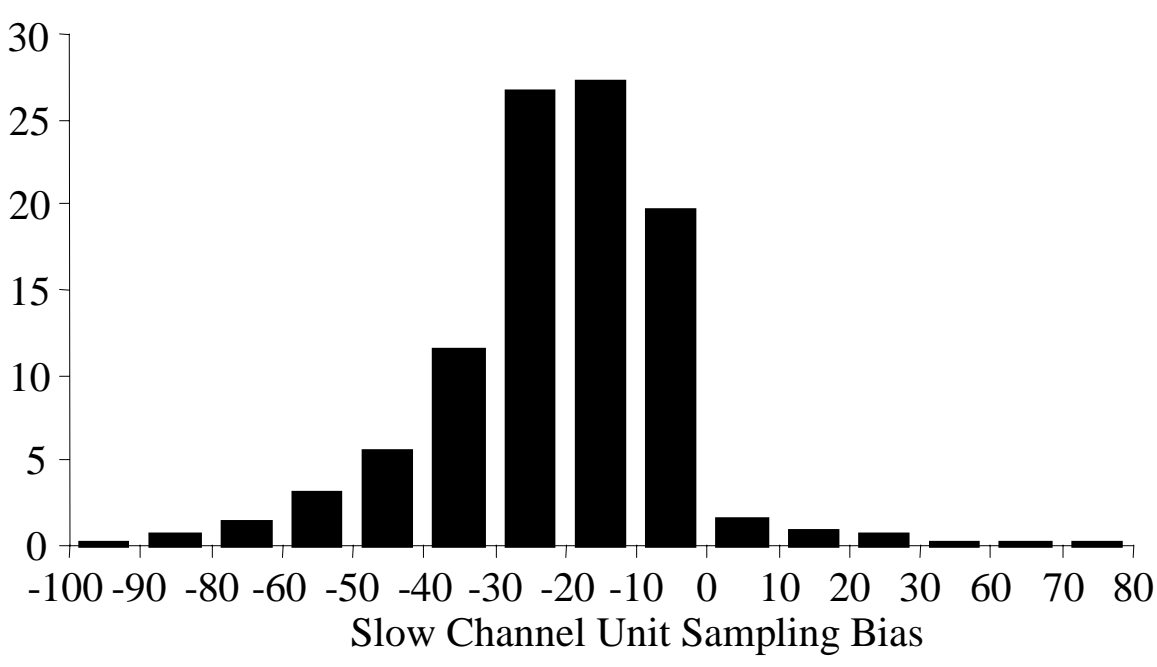

Habitat Sampling, N =897

c.

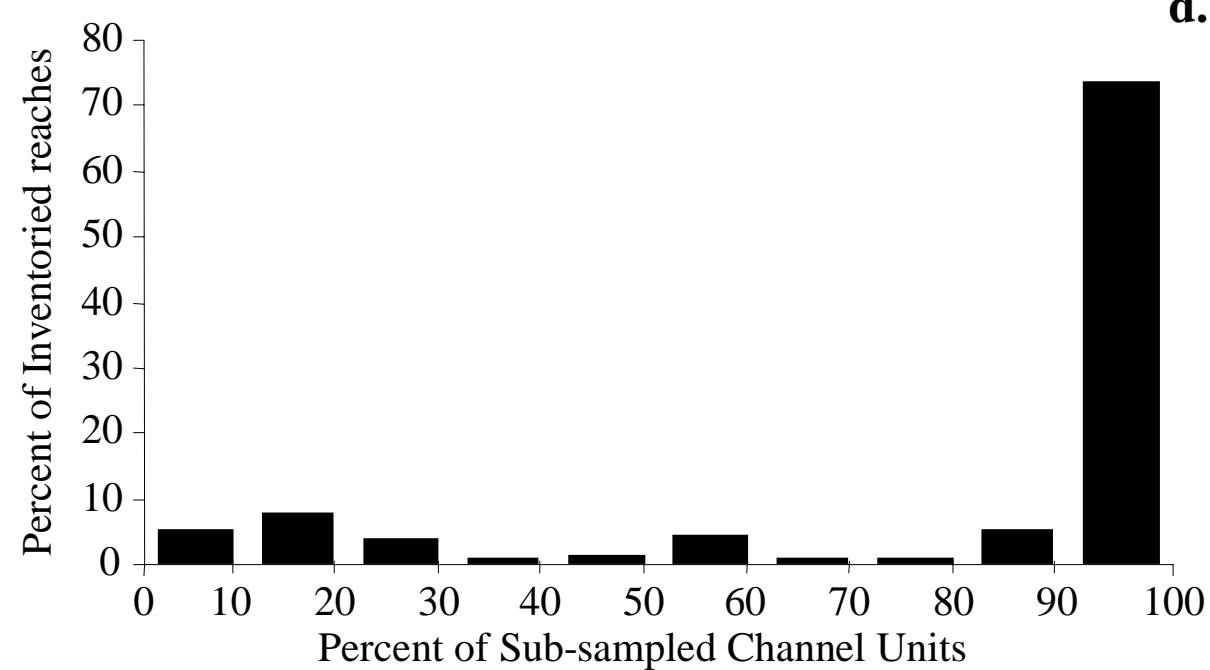

d.

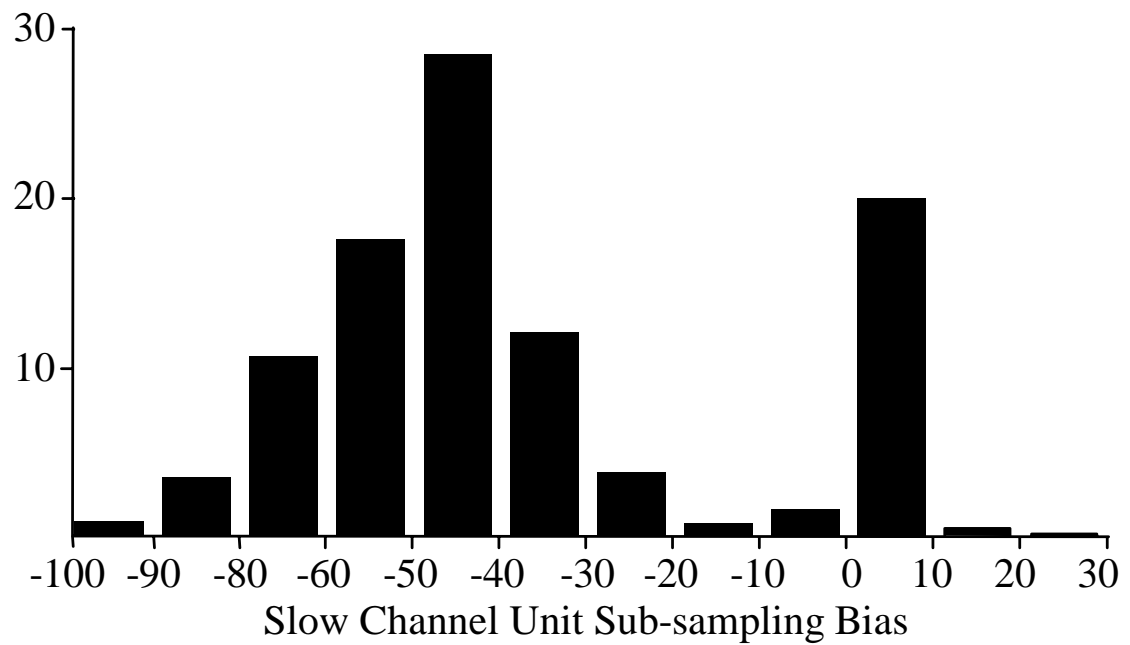

Figure 3. The distributions of (a) the percent of channel units that were sampled for fish, (b) the slow habitat type fish-sampling bias, (c) the percent of channel units sub-sampled for habitat, and (d) the slow habitat type sub-sampling bias. Sub-sampling bias was calculated as the difference between the proportion of slow channel units in a reach and the proportion of sub-sampled units that were slow channel units. 


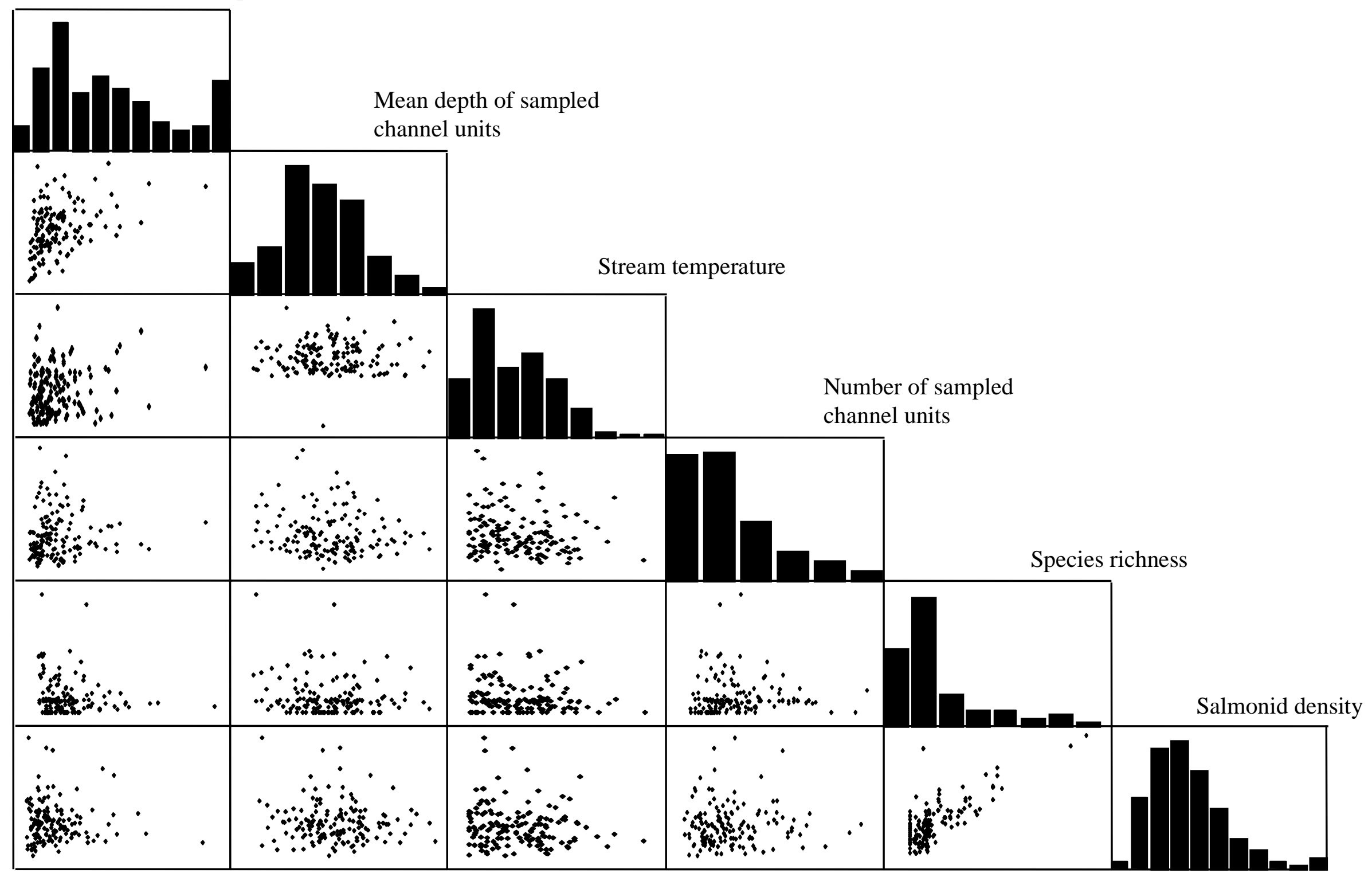

Figure 4. Scatterplot matrix of area sampled, mean depth of sampled channel units, stream temperature during sampling, number of channel units sampled, and the within-reach coefficients of variation for species richness and salmonid density in inventori ed stream reaches. Frequency distributions of each variable are along the main diagonal and pairwise scatterplots are within the body. 


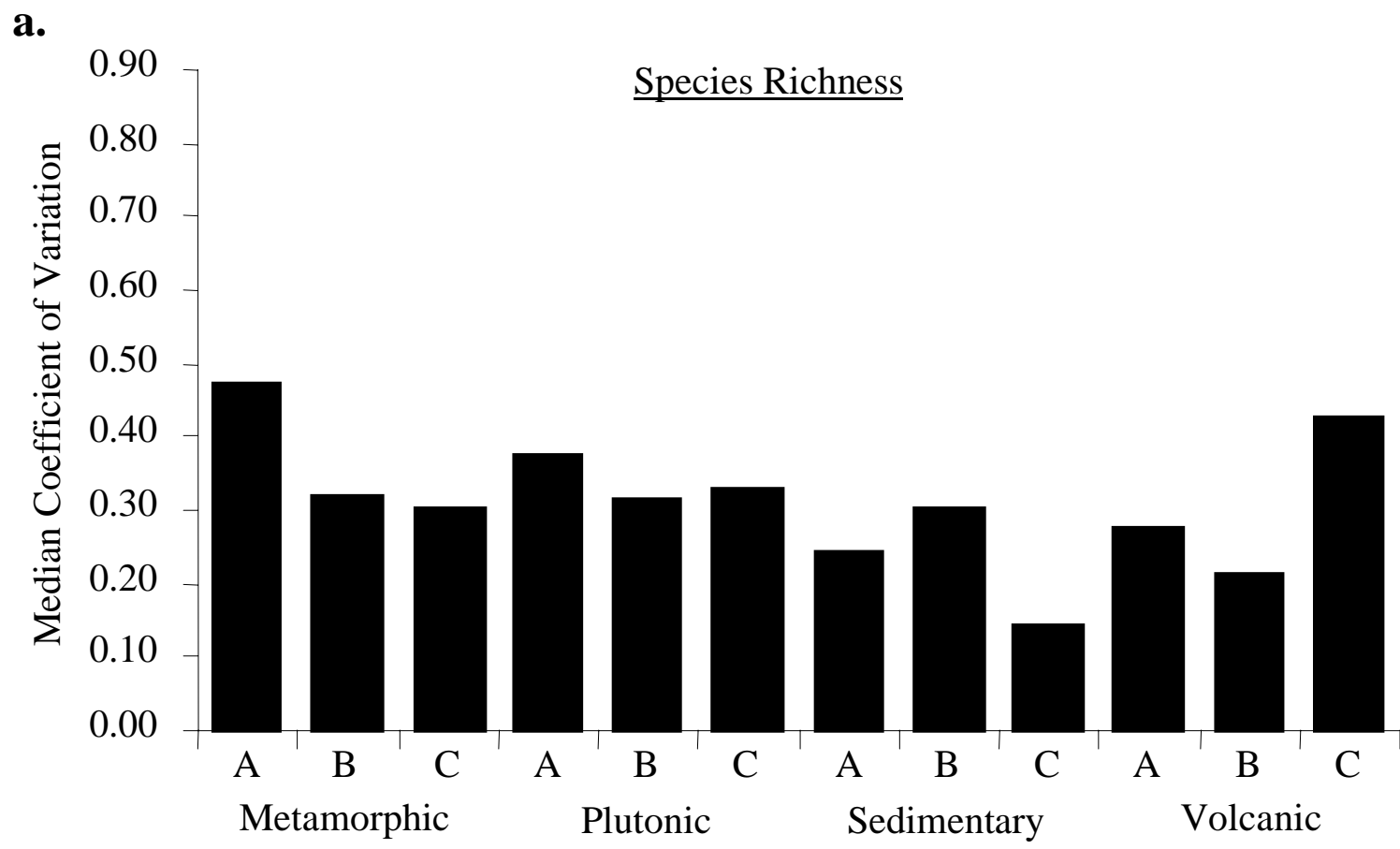

b.

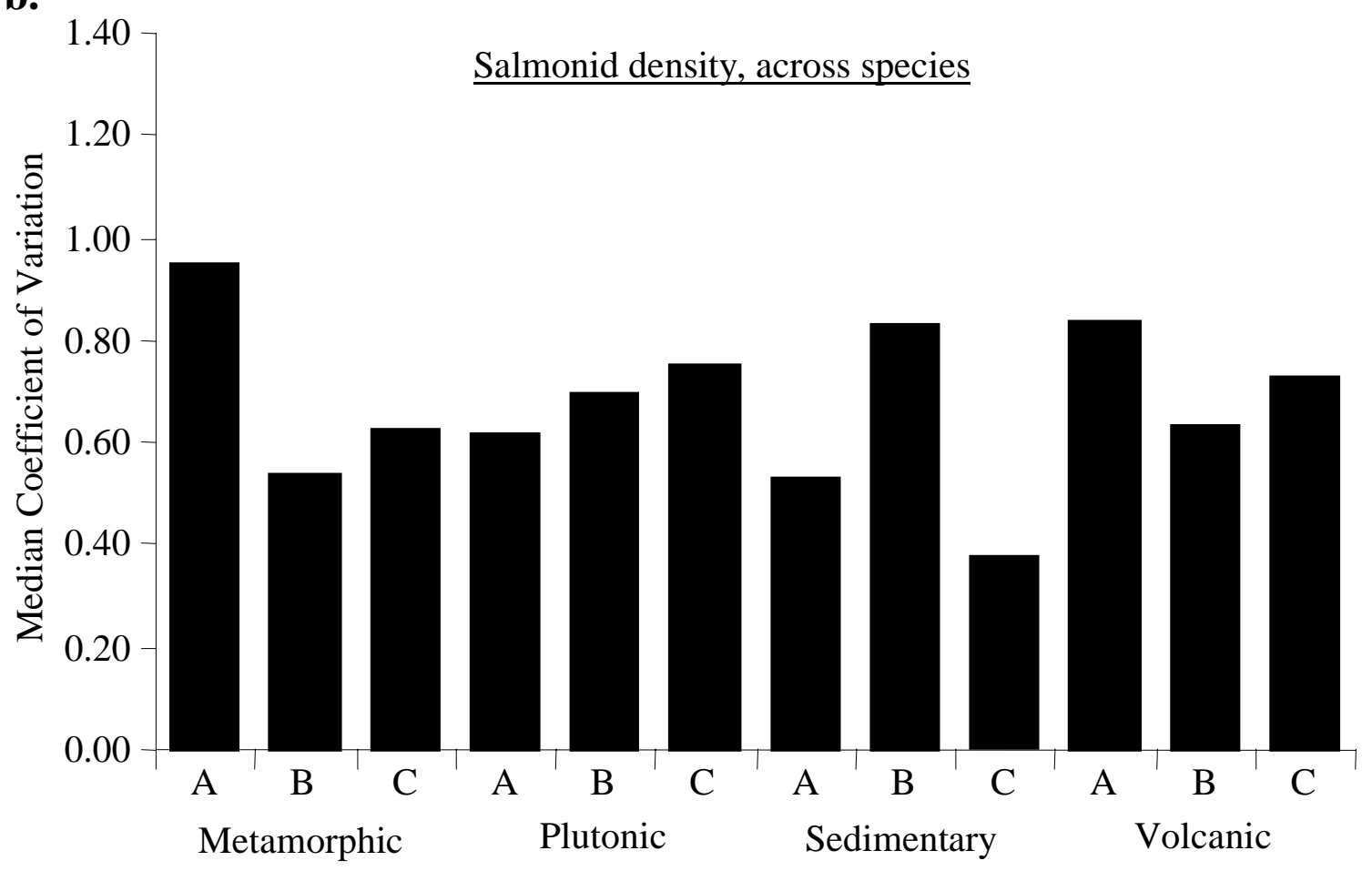

Figure 5. The median within-reach coefficients of variation of (a) species richness and (b) salmonid density, by parent geology and reach type, for inventoried stream reaches. 


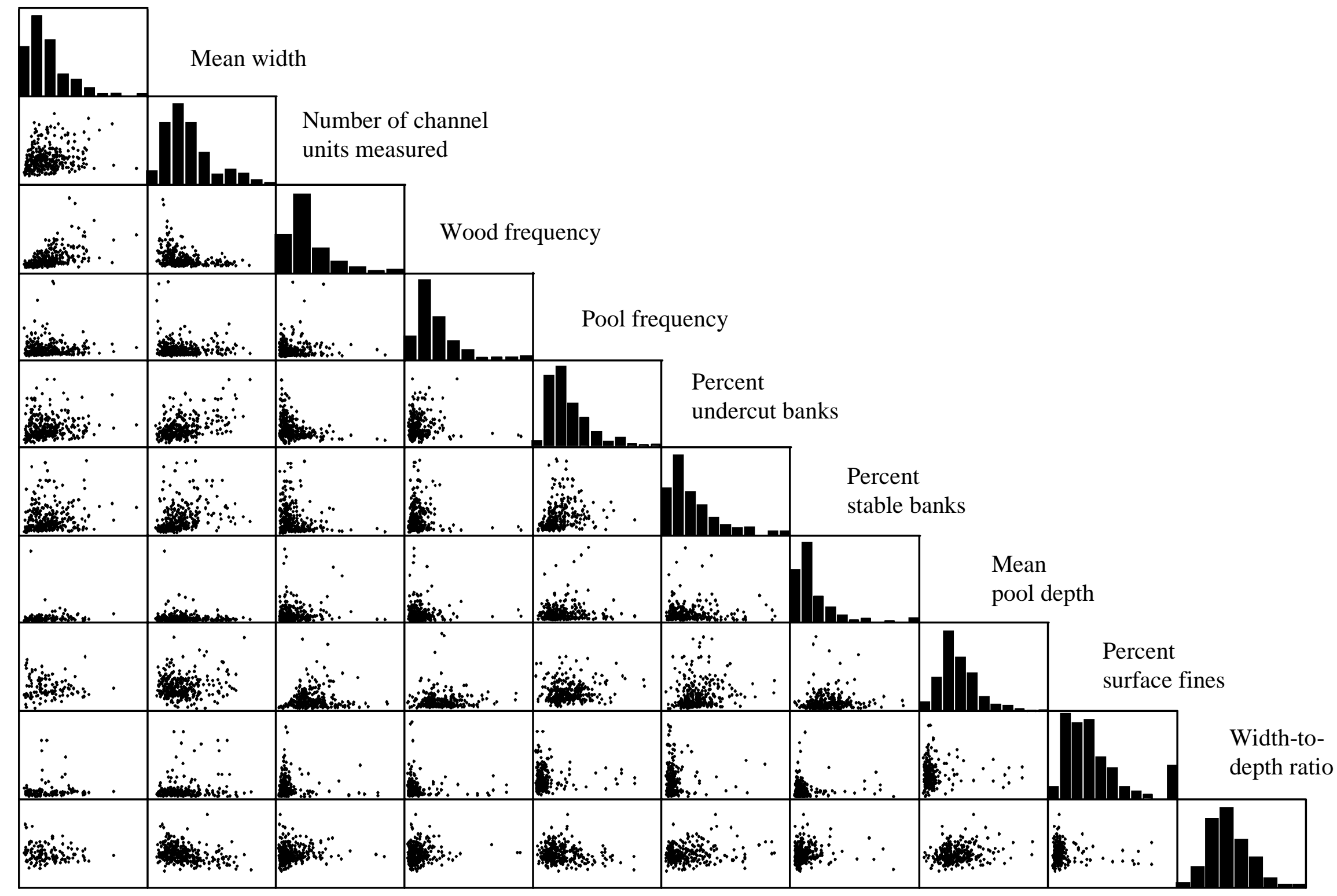

Figure 6. Scatterplot matrix of the total length, mean width, number channel units measured, and the within-reach coefficients of variation of selected habitat characteristics for inventoried stream reaches. Frequency distributions of each variable are along the main diagonal and pairwise scatterplots are within the body. 

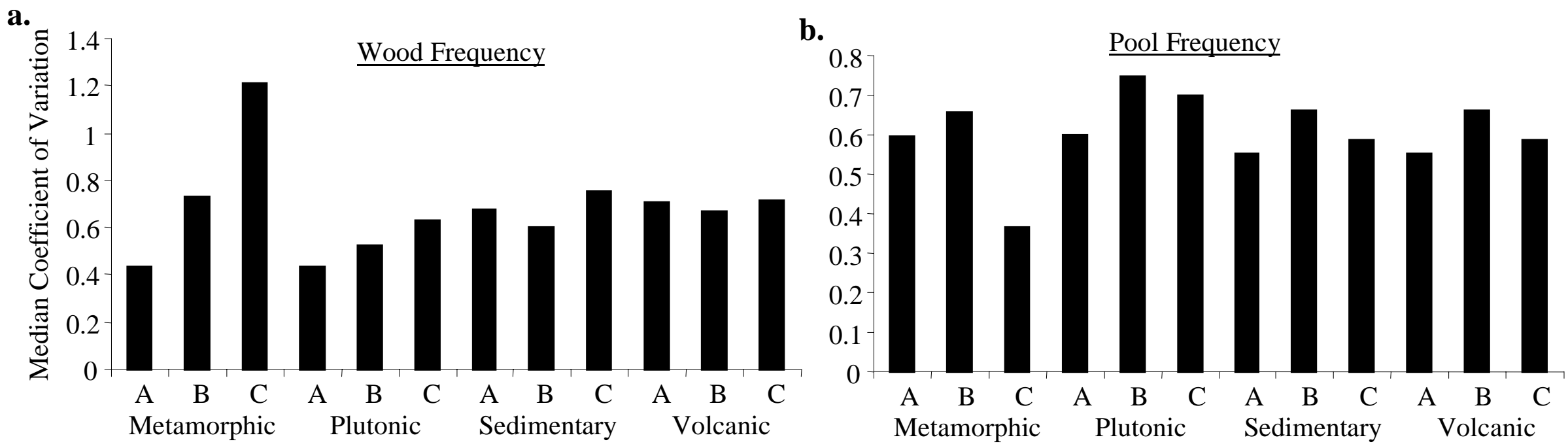

c.

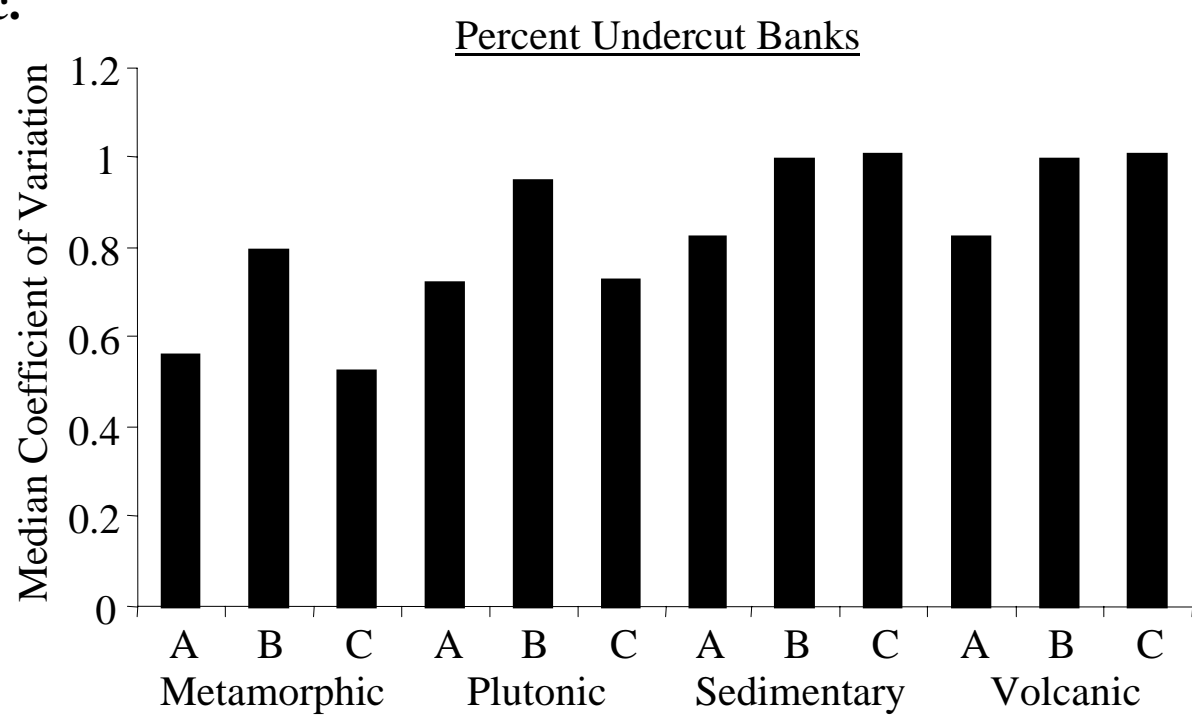

d.

0.35

$\underline{\text { Percent Stable Banks }}$

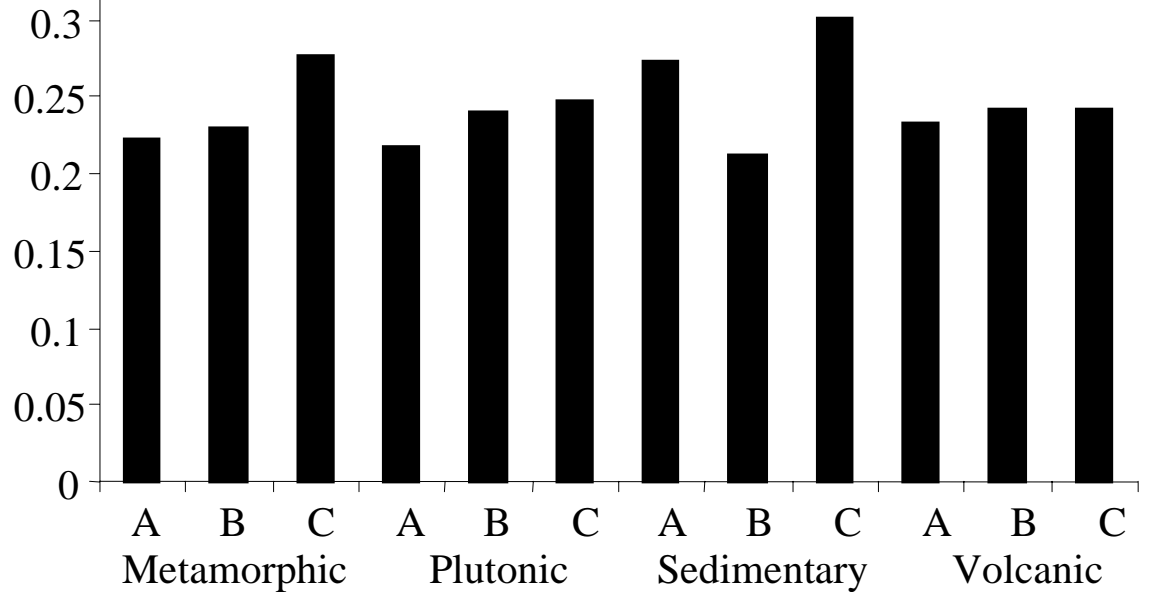

Figure 7. The median within-reach coefficients of variation of (a) wood frequency, (b) pool frequency, (d) percent undercut bank, and (d) percent stable banks, by parent geology and reach type, for inventoried stream reaches. 

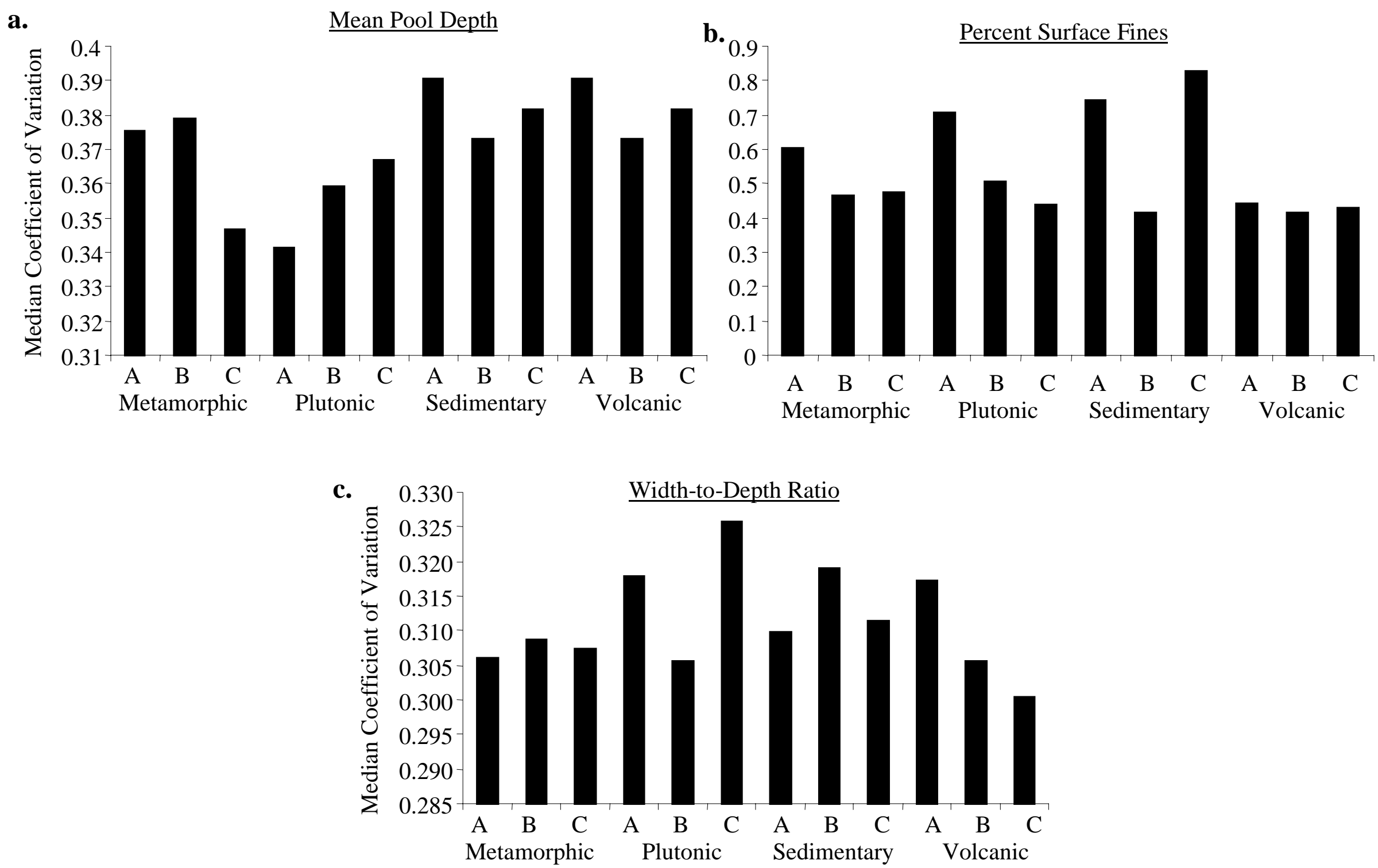

Figure 8. The median within-reach coefficients of variation of (a) mean pool depth, (b) percent surface fines, and (c) width-to-depth ratio, by parent geology and reach type, for inventoried stream reaches. 
a.

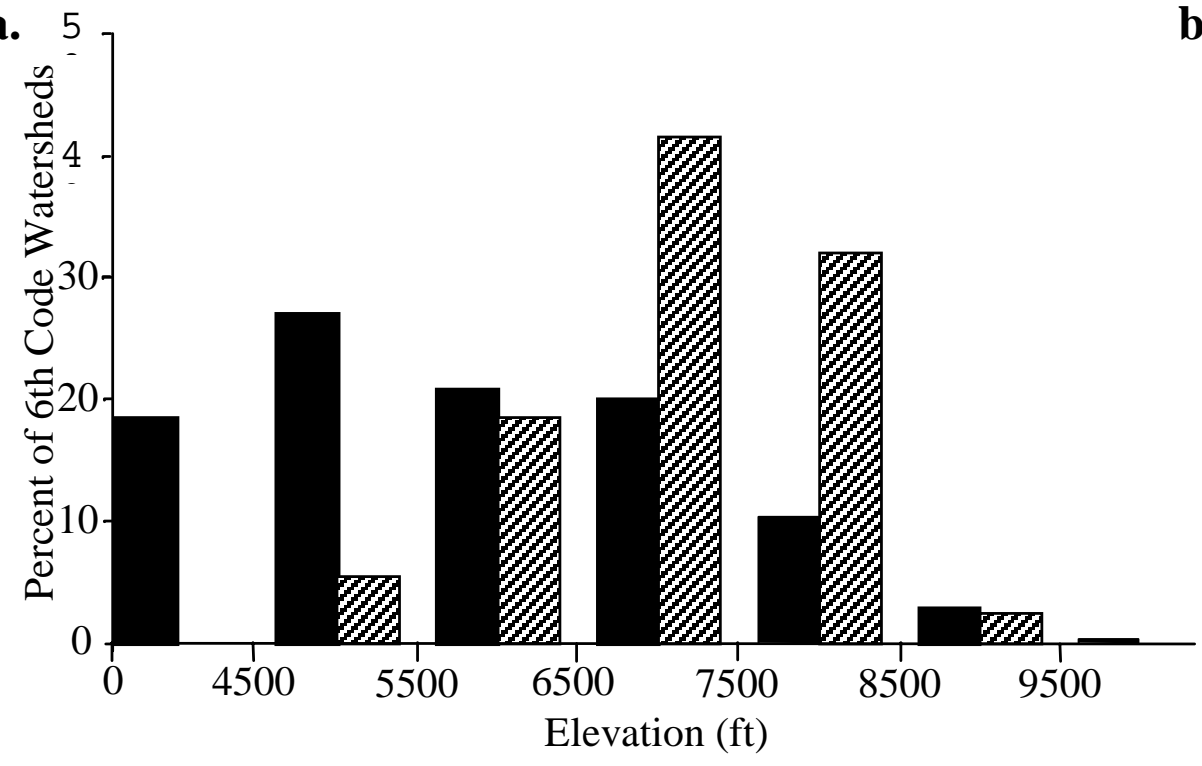

c.

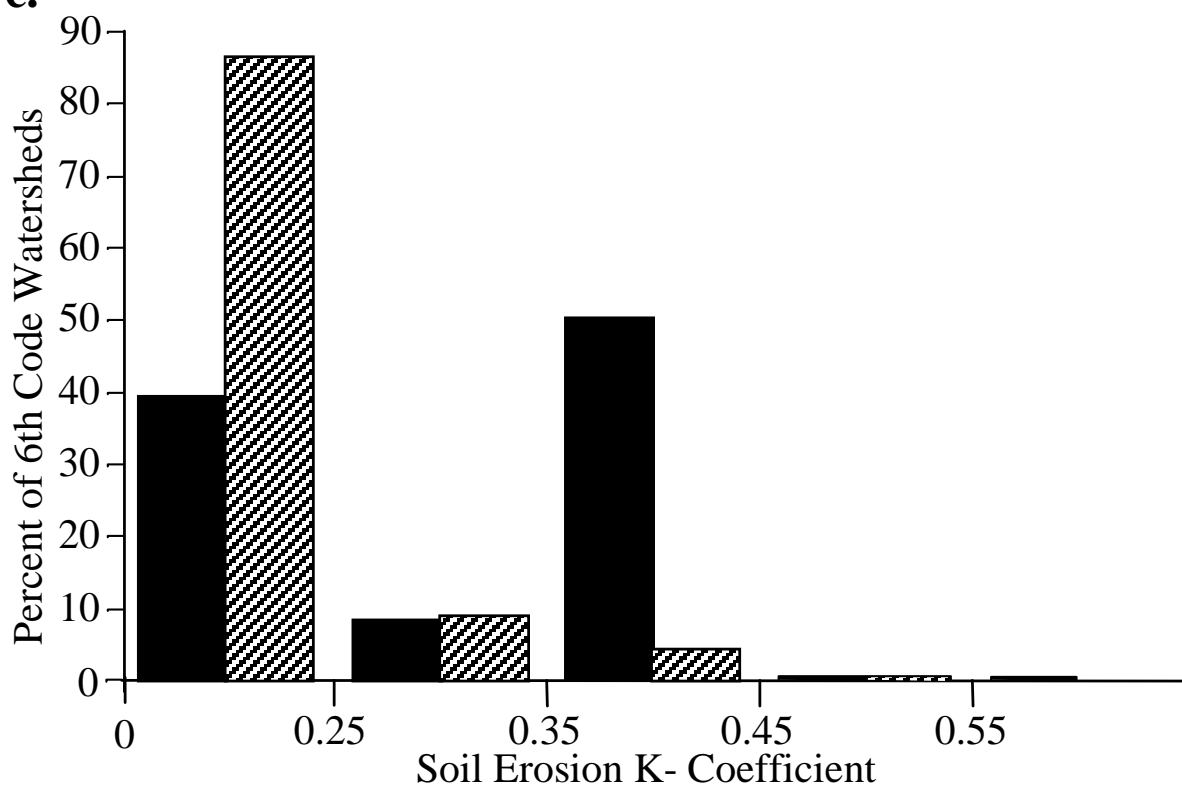

b. 50

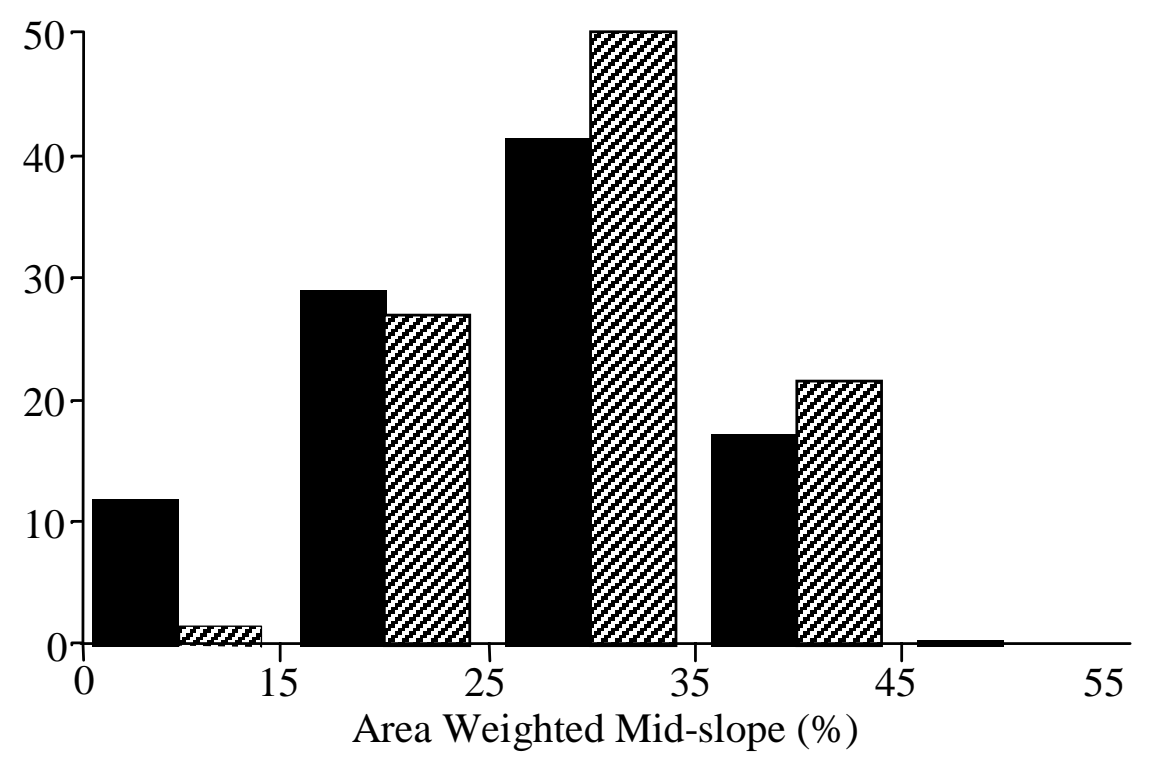

d.

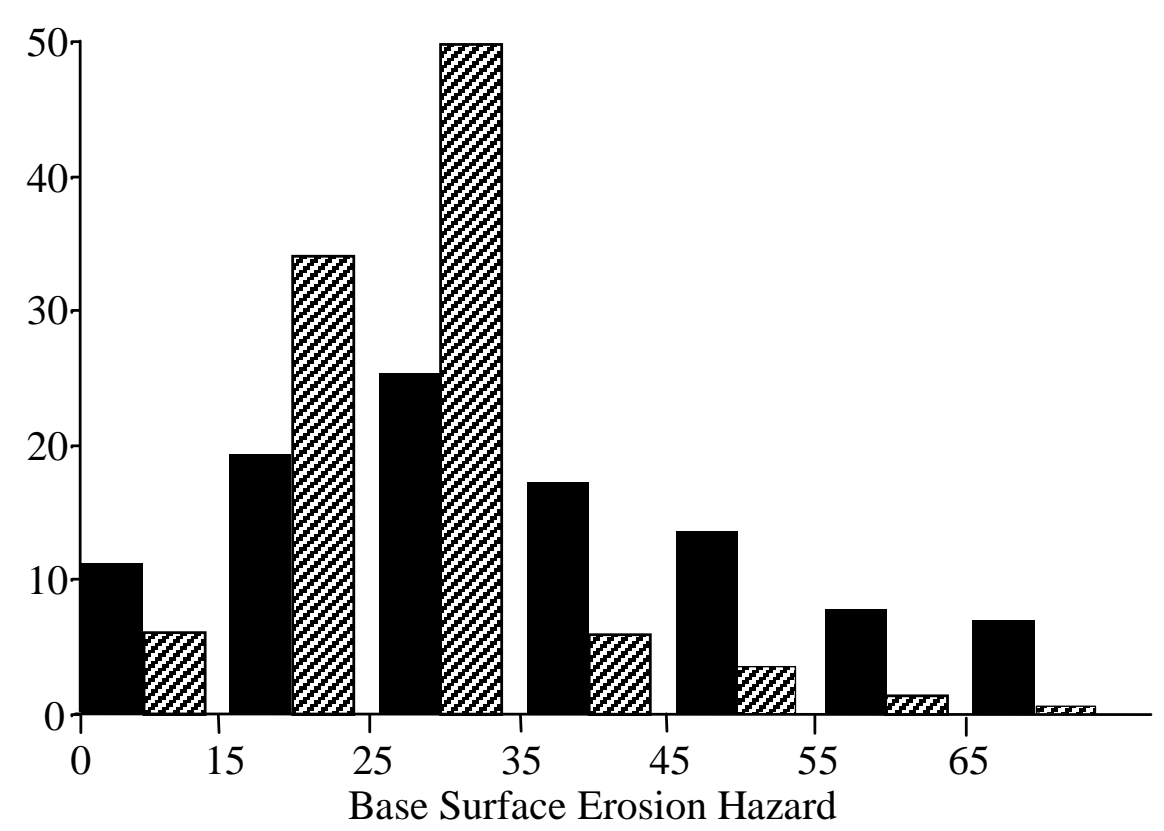

Figure 9. The frequency distributions of (a) elevation, (b) valley slope, (c) soil erosion coefficient, and (d) a surface erosion hazard for 6th code watersheds in the Interior Columbia River Basin with $\geq 75 \%$ Forest Service ownership (solid) and 6th code watersheds containing inventoried streams (cross-hatched). 


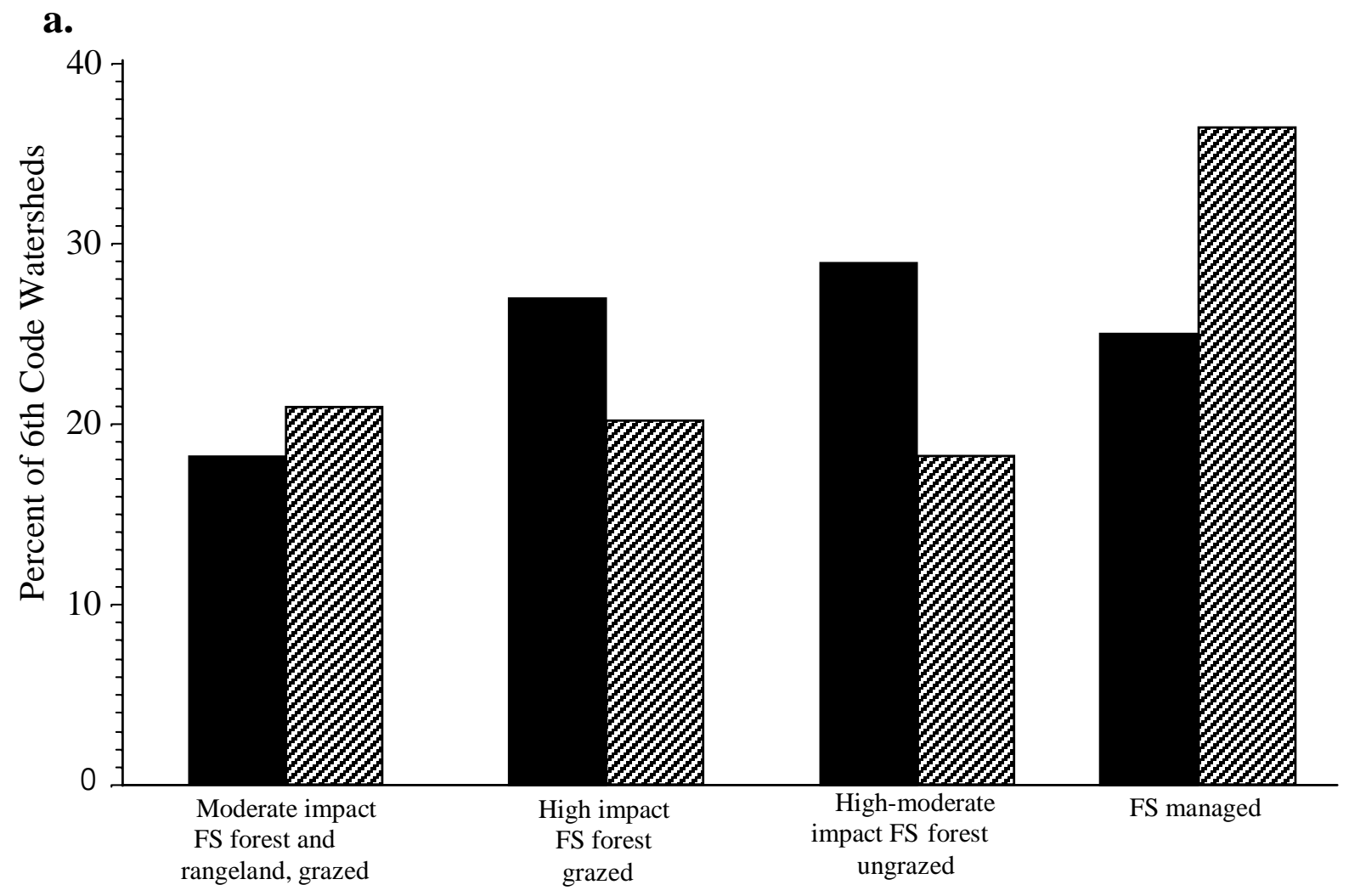

b.

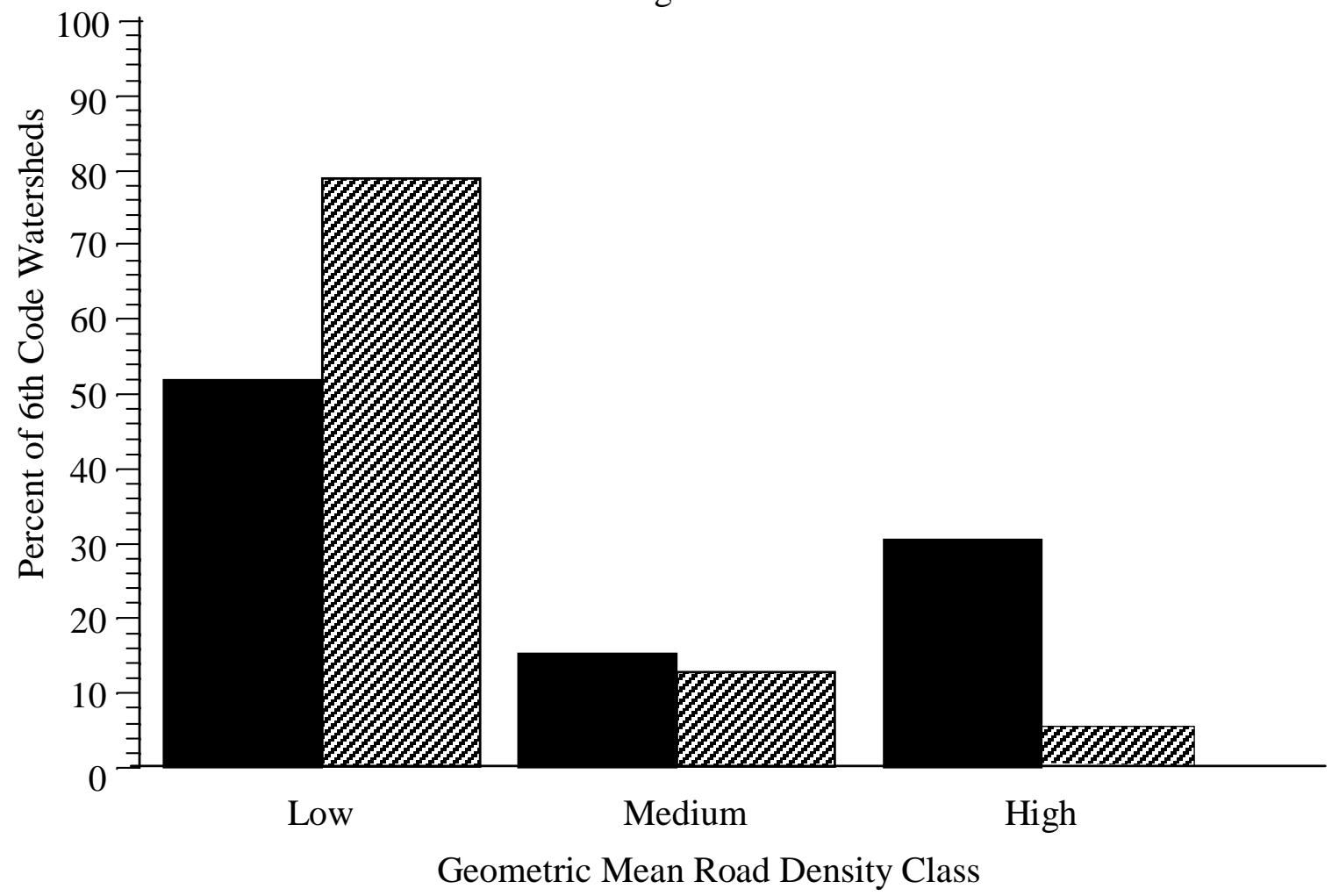

Figure 10. The frequency distributions of (a) management cluster type and (b) geometric mean road density classes for 6th code watersheds in the interior Columbia River Basin with $\geq 75 \%$ Forest Service ownership (solid) and 6th code watersheds containing inventoried streams (cross-hatched). 

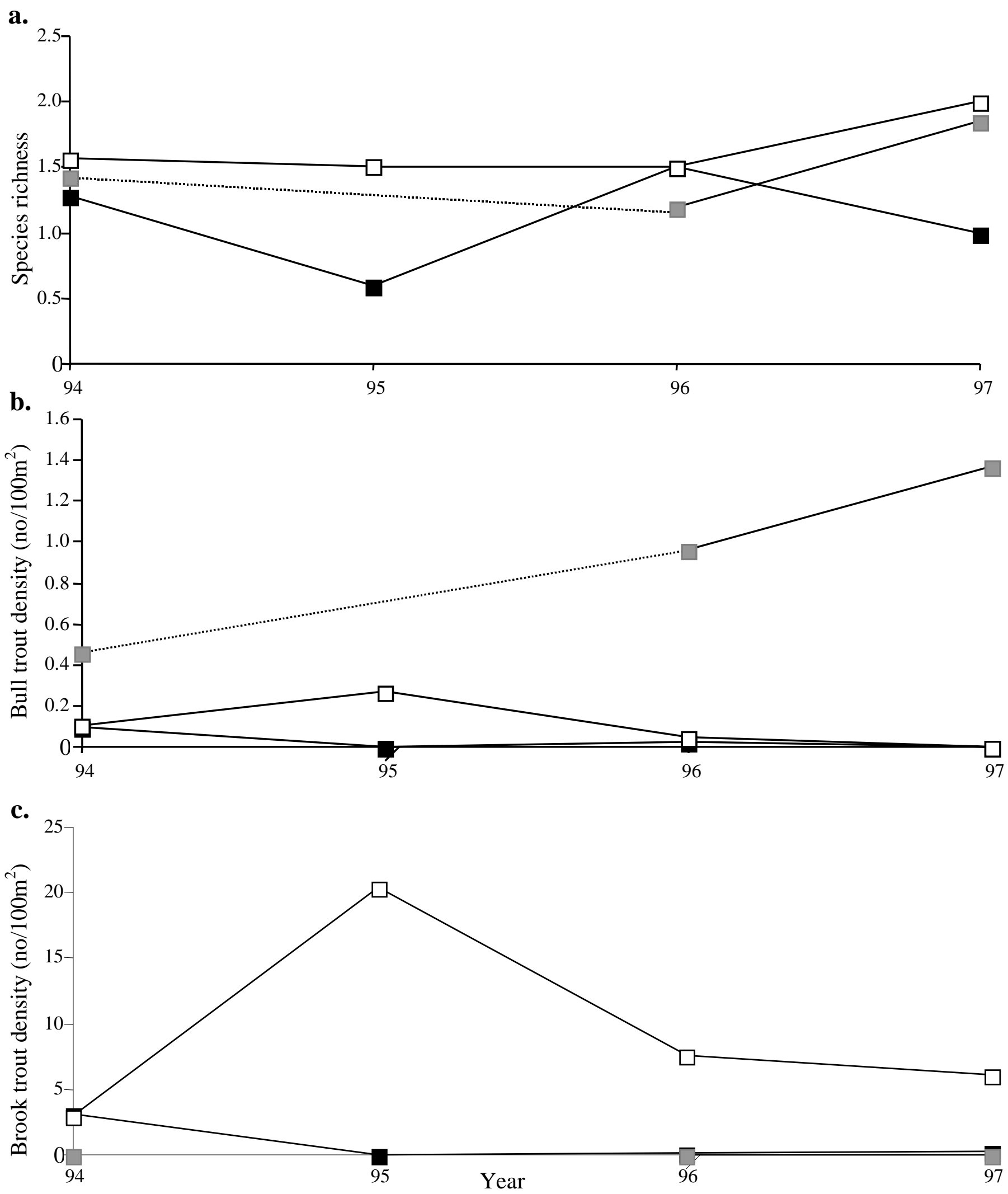

Figure 11. Mean (a) species richness, (b) bull trout density, and (c) brook trout density in streams in unburned-unlogged (white), burned-unlogged (gray), and burned-logged (black) catchments, by year. Broken line indicates missing data for streams in burned-unlogged catchments. 

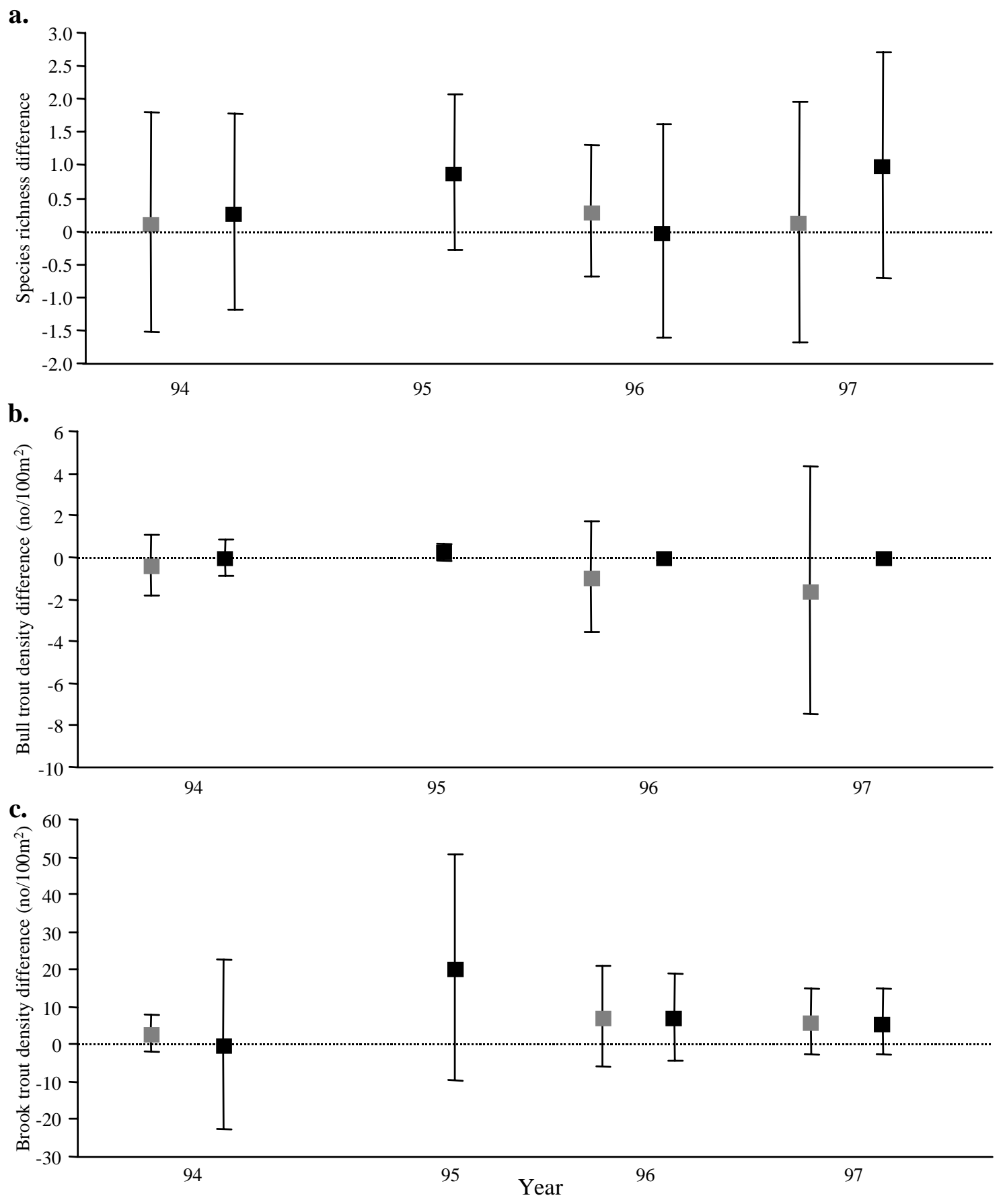

Figure 12. The mean differences between streams in unburned-unlogged catchments and streams in burned-unlogged (gray), and burned-logged (black) catchments for (a) species richness, (b) bull trout density, and (c) brook trout density, by year. Brackets are $95 \%$ confidence intervals and dotted line represents no change. 

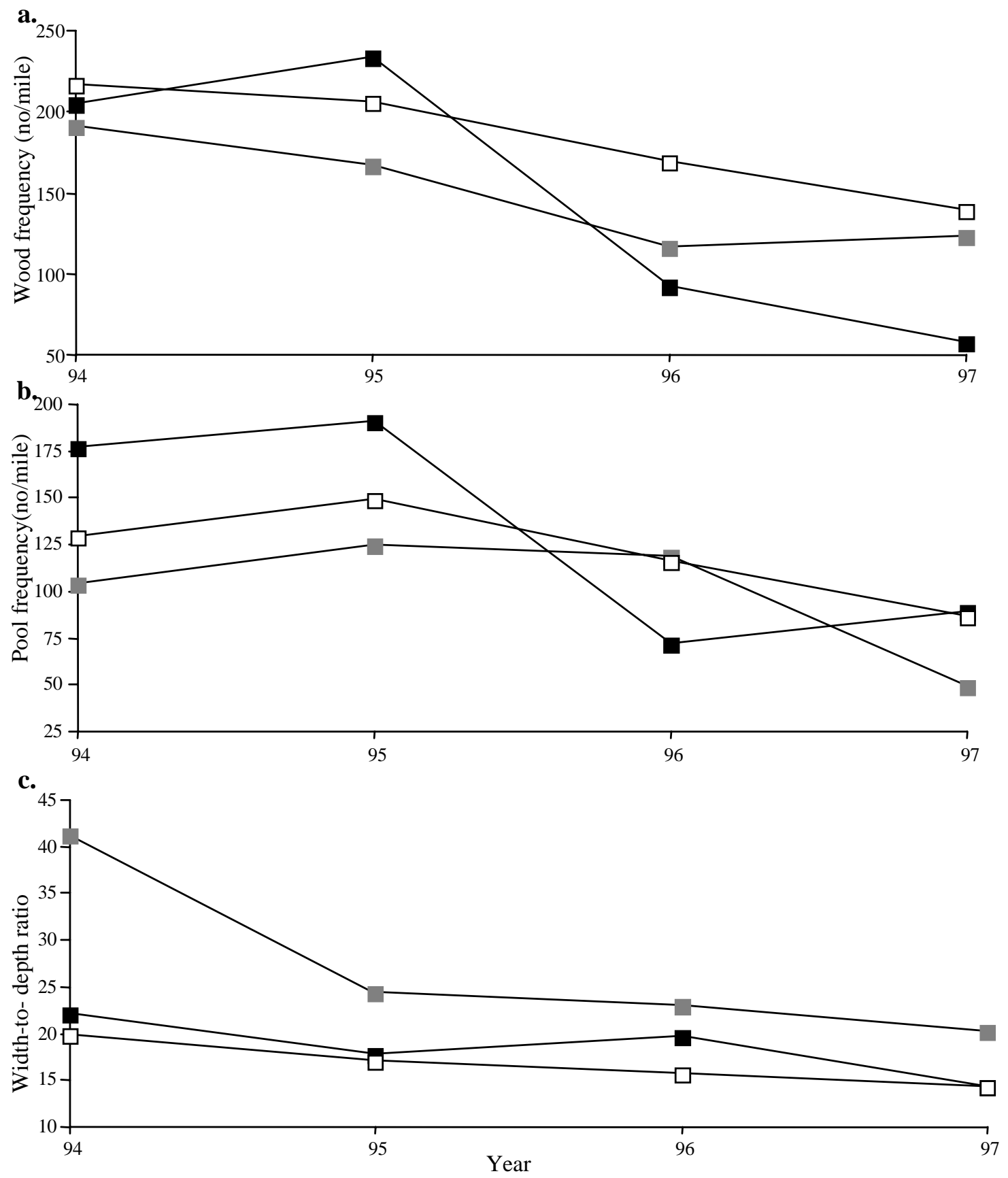

Figure 13. Mean (a) wood frequency, (b) pool frequency, and (c) width-to-depth ratios of streams in unburned-unlogged (white), burned-unlogged (gray), and burned-logged (black) catchments, by year. 


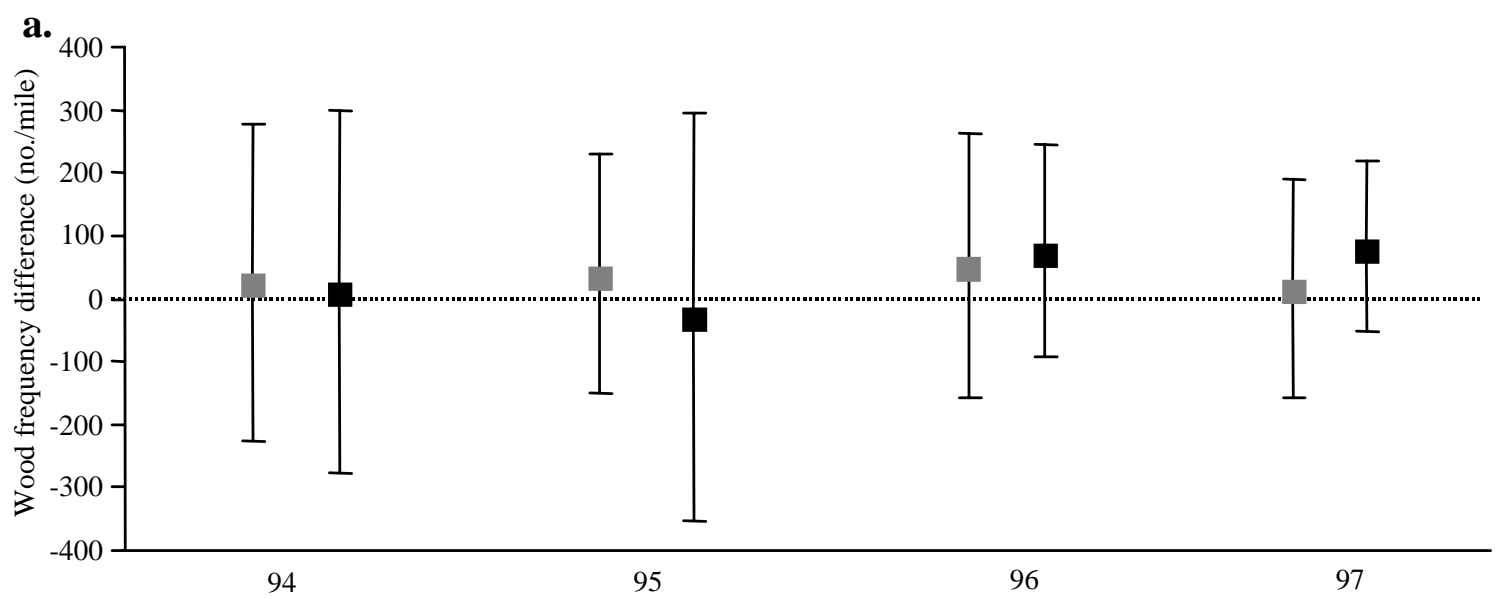

b.
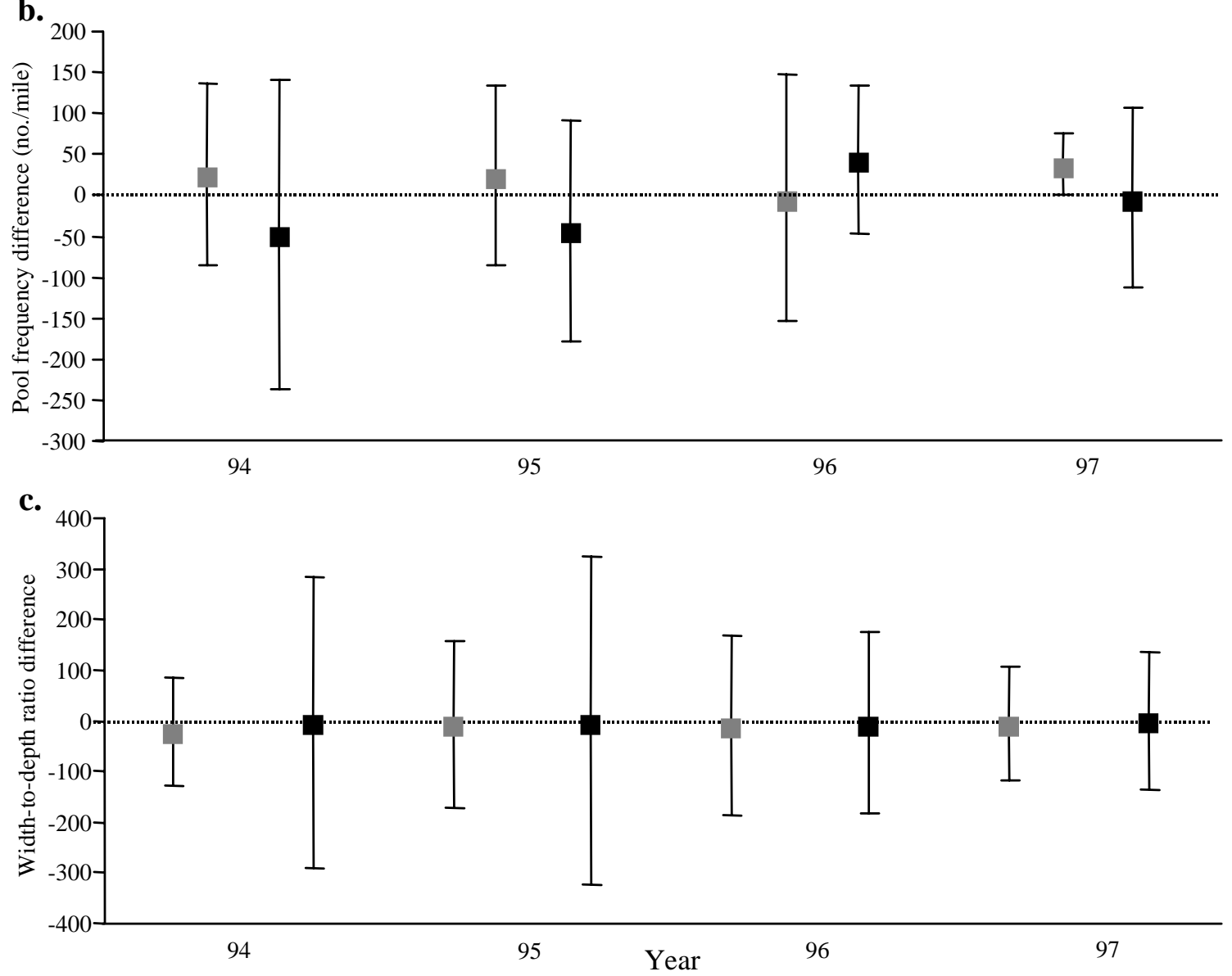

Figure 14. The mean differences between streams in unburned-unlogged catchments and streams in burned-unlogged (gray), and burned-logged (black) catchments for (a) wood frequency, (b) pool frequency, and (c) width-to-depth ratio, by year. Brackets are 95\% confidence intervals and dotted line represents no change. 
a.

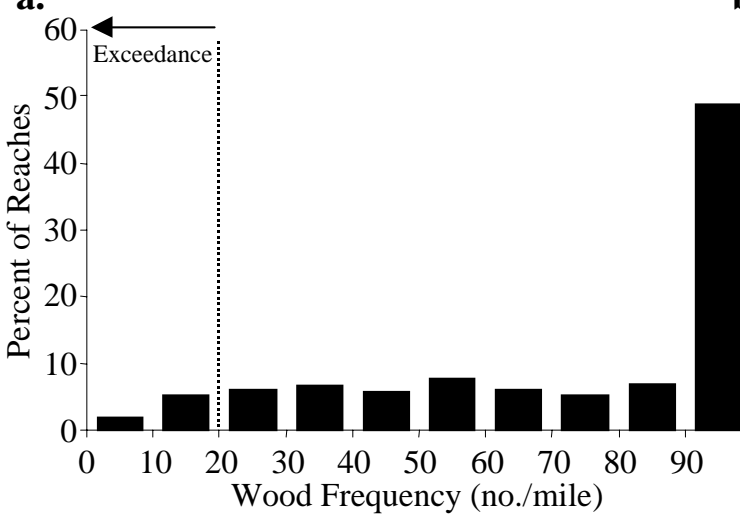

b.

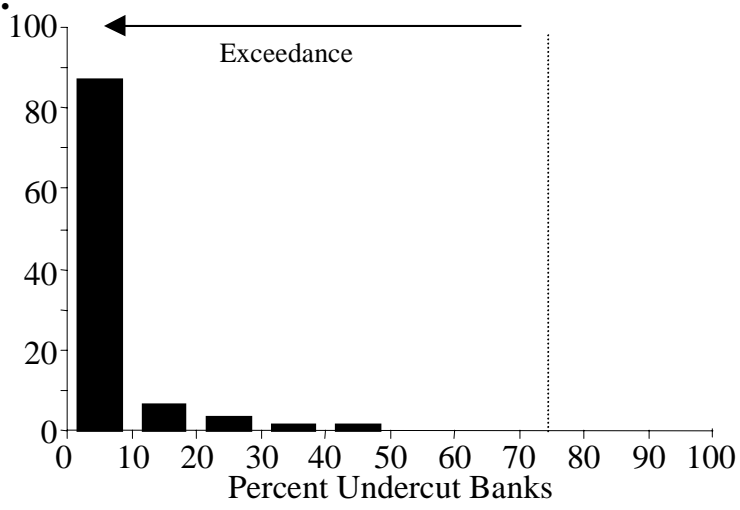

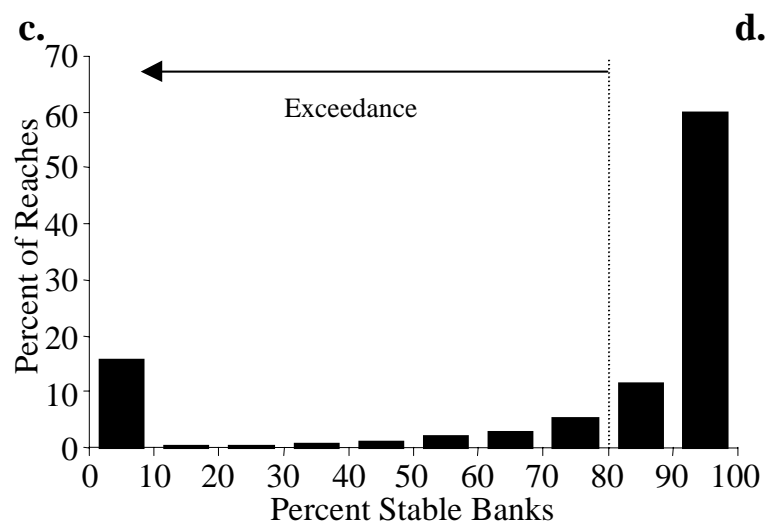

d.
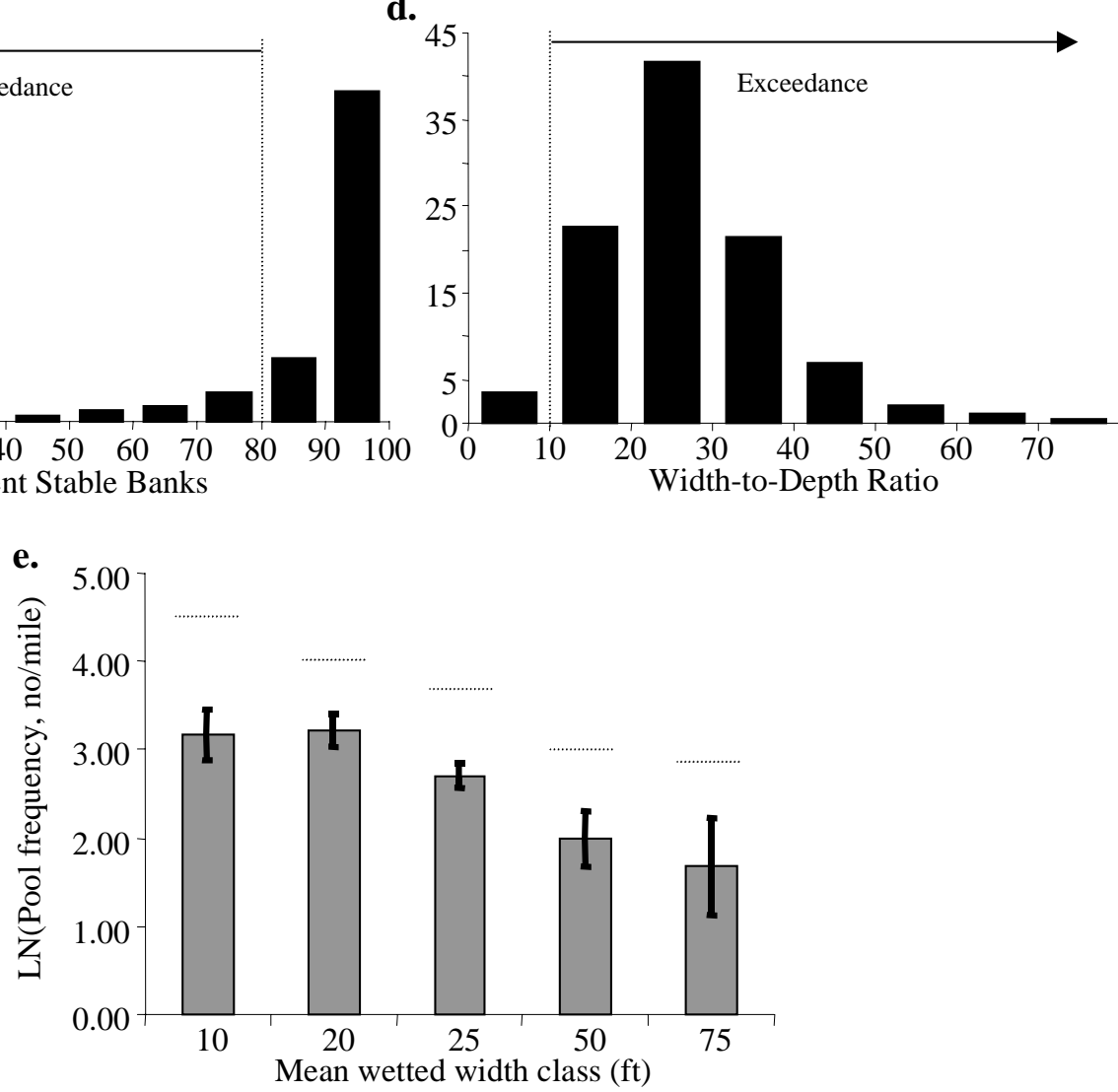

Figure 15. The distributions of (a) wood frequency, (b) undercut banks, (c) stable banks, (d) width-to-depth ratio and (e) mean pool frequency, by channel width class, for natural condition stream reaches in the Salmon River Basin, Idaho. Bars are 95\% confidence intervals and broken lines represent PACFISH riparian management objective thresholds. 